\title{
SNOW FORCES
}

\author{
By Bruno Salm \\ (Eidgenössisches Institut für Schnee- und Lawinenforschung, 726o Weissfluhjoch/Davos, \\ Switzerland)
}

\begin{abstract}
Snow forces are understood as forces originating from a very slow motion of the seasonal snow cover and acting on boundaries confining it. They depend on the total water-equivalent (a statistical magnitude with a certain probability of occurrence) and on mechanical characteristics of snow. The approximation of considering of snow as a Newtonian liquid fits the requirements for applications best. In this the only mechanical characteristics to be taken into account, besides density, are shear viscosity and Poisson's ratio. They depend strongly on the snow structure. Generalizations are shown in which the snow cover is subdivided into layers having constant (Newtonian) properties. Non-Newtonian behaviour is also mentioned.

RÉsumé. Forces de la neige. Des forces de la neige - comprises comme forces qui agissent sur les bords de la couche saisonnière de la neige et qui sont causées par son mouvement lent — dépendent de la valeur en eau de la couche totale de la neige (une valeur statistique qui se produit avec une certaine probabilité) et des propriétés mécaniques de la neige. Au niveau des problèmes pratiques, la neige se comporte approximativement comme un liquide Newtonien avec une densité et des propriétés mécaniques viscosité au cisaillement et nombre de Poisson qui dépendent fortement de la structure. Comme généralisation, le manteau neigeux est subdivisé d'une part en strates à propriétés mécaniques constantes (Newtoniennes) et d'autre part les propriétés non Newtoniennes sont mentionnées.

Zusammenfassung. Schneekräfte. Schneekräfte - verstanden als Kräfte aus der schleichenden Bewegung der Saisonschneedecke auf sie begrenzende Randflächen - hängen ab vom Wasserwert der Gesamtschneedecke (ein statistischer Wert, behaftet mit einer Wahrscheinlichket des Auftretens) und von mechanischen Eigenschaften von Schnee. Für praktische Anwendungen eignet sich vor allem eine angenäherte Betrachtung von Schnee als Newtonsche Flüssigkeit. Als mechanische Eigenschaften treten dabei neben der Dichte nur die Scherzähigkeit und die Poissonsche Zahl auf, welche ihrerseits stark strukturabhängig sind. Verallgemeinerungen werden gezeigt, in denen die Schneedecke in Schichten mit konstanten (Newtonschen) Eigenschaften aufgeteilt wird, ferner wird auf nicht-Newtonsches Verhalten hingewiesen.
\end{abstract}

\section{List of SyMBOLS}

$A$ Interval between two structures on the same contour-line, measured across the slope, or

Amplitude of the bed topography of the ground.

a Characteristic of snow determining $\epsilon$, or

Factor introduced by Haefeli for calculation of $\eta_{\mathrm{F}}$.

$b \quad$ Half of the length $l$ of a supporting structure measured across the slope, or Half of the segment over which an external stress acts on the surface of the snow cover.

c Cohesion (friction, independent of normal stress and velocity), or

Factor taking variable viscosity into account.

$D$ General thickness of the snow cover perpendicular to the ground.

$D_{\mathrm{f}}$ Fictitious snow thickness perpendicular to the ground.

$d^{\prime}$ Stagnation depth perpendicular to the ground.

$f_{\mathbf{R}} \quad$ End-effect factor for the calculation of $S_{\mathbf{R}}$ '.

$g$ Acceleration due to gravity.

$H$ General vertical snow depth.

$k$ Yield stress.

$L \quad$ Characteristic length, or

Distance between two rows of supporting structures measured parallel to ground.

$l$ Length of a supporting structure measured across the slope.

$\Delta l \quad$ Length of application of the end-effect forces on supporting structures measured across the slope.

$m$ Viscous analogue of the cross-section number or the inverse of the viscous analogue of Poisson's ratio. 
$\mathcal{N}$ Glide factor.

$n$ Relative glide velocity.

$p$ External normal stress acting on the surface of the snow cover.

$R^{\prime} \quad$ Resultant force per unit length on a supporting plane.

$r$ Radius in polar coordinates.

$S_{\mathrm{N}}{ }^{\prime} \quad$ Snow force parallel to the slope per unit length on a supporting plane which is unconfined in its length across the slope (creep and glide force).

$S_{\mathrm{Nb}^{\prime}}$ Part of $S_{\mathrm{N}^{\prime}}$ acting on one horizontal crossbeam.

$S_{\mathrm{Q}^{\prime}}$ Snow force perpendicular to the slope per unit length on a supporting plane.

$S_{\mathrm{Qb}^{\prime}} \quad$ Part of $S_{\mathbf{Q}^{\prime}}$ acting on one horizontal crossbeam.

$S_{\mathrm{R}}{ }^{\prime}$ Additional snow force parallel to the slope and working on the lateral edges of the supporting plane (end-effect force).

$s$ Vertical snow load on a roof.

$s_{\mathrm{g}}$ Snow load on the ground.

$t$ Temperature [in $\left.{ }^{\circ} \mathrm{C}\right]$.

$U$ Characteristic velocity.

$u, v, w$ Velocity components of a particle in a system of coordinates $x, y$ and $z$.

$x, y, z$ Rectangular Cartesian coordinate system.

$y_{\mathrm{b}}$ Length of the back-pressure zone parallel to the slope.

$\alpha$ Angle in polar coordinates, or

Factor introduced by Haefeli for the calculations of $\eta_{\mathrm{F}}$.

$\beta$ Angle of roof slope, or

Creep angle, i.e. angle between the velocity vector of a particle in the neutral zone without gliding and the direction parallel to the ground.

$\gamma$ General density (force per unit volume).

$\gamma_{0}$ Characteristic density.

$\gamma_{i}$ Density of ice, or

Constant snow density of the $i$ th layer within a snow cover.

$\delta$ Thickness of a shear boundary layer, or

Angle between an external force acting on the snow surface and the snow surface.

$\epsilon$ Angle between $R^{\prime}$ and the direction parallel to the slope.

$\zeta$ Pressure coefficient at rest.

$\eta_{\mathrm{F}}$ Efficiency of a supporting structure in regard to snow pressure.

$\lambda_{0}$ Wavelength of the bed topography of the ground.

$\mu$ Shear viscosity (defined by the state of stress of simple shearing $\sigma_{2}=-\sigma_{1}$ and $\sigma_{3}=0$ ), or

Snow-load coefficient.

$\rho_{0} \quad$ Characteristic density (mass per unit volume).

$\sigma_{1}, \sigma_{2}, \sigma_{3}$ Principal stresses.

$\sigma_{x}, \sigma_{y}, \sigma_{z}$ Normal stresses in a system of coordinates $x, y$ and $z$.

$\tau_{x y}, \tau_{x z}, \tau_{y z}$ Shear stresses in a system of coordinates $x, y$ and $z$ respectively.

$\Phi$ Function used by Haefeli for the calculation of snow pressure.

$\psi$ Angle of the slope.

\section{Definitions}

Back pressure zone. The up-hill zone within which the state of the neutral zone is noticeably perturbed by a rigid wall.

Constitutive equation. An equation establishing a relation between static (e.g. stress) and kinematic (e.g. rate of deformation) tensors. 
Creep force. The part of the force on a rigid obstacle originating from creeping.

Creeping. The rates of deformation in the continuum snow, i.e. the symmetric part of the tensor of the velocity-vector gradient.

Creep number. Dimensionless number governing the viscous creep, if snow is considered as a Newtonian fluid (product of Froude and Reynolds number).

Critical slope angle. The slope angle where one principal stress vanishes (changes from compressive to tensile normal stress).

Glide force. The part of the force on a rigid obstacle originating from gliding.

Gliding. The movement of the entire sloping snow-pack caused by a high gradient of the velocity parallel to the ground in a comparatively small layer near the ground. The process is strongly related to the ground characteristics.

Neutral zone. The state of the snow cover where all gradients parallel to the ground totally disappear (gradients of the thickness of the snow-pack and the individual layers, of slope angle, characteristics of the material and of the snow-ground interface conditions).

Pressure at rest. The (principal) stress parallel to the ground originating from the uniaxial state of deformation in the neutral horizontal snow cover.

Viscous fluid

- Newtonian fluid. A fluid with a constitutive equation relating stresses and rates of deformation linearly. Only two constant characteristics of the material occur for a given snow type and temperature (e.g. shear viscosity and cross-section number).

- quasi-Newtonian fluid. A first step in the generalization of a Newtonian fluid, where the two characteristics of the material (e.g. shear viscosity and cross-section number) are no longer constant but depend on the invariants of the stress tensor.

-non-Newtonian fluid. The most general case, where the tensor of the rates of deformation depends on the unit tensor, the tensor and the square of the tensor of stresses, and on three associated independent functions each containing the invariants of the stress tensor (Reiner-Rivlin fluid).

\section{General comments and definitions}

Snow forces are understood as forces of the continuum snow acting on boundaries with certain boundary conditions. In applied snow mechanics two different types of such forces are of interest.

The first type occur with rapidly moving snow (avalanches). Here two characteristic numbers are predominant in governing the processes: First the Froude number

$$
(F r)=\frac{g L}{U^{2}},
$$

a measure of the relative importance of potential and kinetic energy. $g$ is the acceleration due to gravity, $L$ a characteristic length and $U$ a characteristic velocity of the problem. Secondly the Reynolds number

$$
(R e)=\frac{\rho_{0} U L}{\mu},
$$

a measure of the relative importance of kinetic energy and viscous dissipation. $\rho_{0}$ is a characteristic density and $\mu$ the (constant) coefficient of shear viscosity.

The second type occur with slow movements of natural, undisturbed snow where the kinetic energy is negligible compared with viscous dissipation. As in the case of avalanches, the significant acting body force is gravity with a corresponding potential energy. Therefore the Reynolds number becomes very small and the Froude number very large. The product of both - it could be called "Creep number"- 


$$
(C r)=\frac{g \rho_{0} L^{2}}{\mu U}=\frac{\gamma_{0} L^{2}}{\mu U}
$$

governs the processes and is a measure of the relative importance of potential energy and viscous dissipation. Slow-moving snow is generally considered as a non-Newtonian fluid with Newtonian behaviour only in a confined range of low stresses. Thus Equation (3), involving a constant viscosity, is not generally valid. If $\gamma_{0}$ and $\mu$ remain constant, from the required constancy of $(\mathrm{Cr} r)$ it can be concluded that $U$ increases with the square of $L$ and the stresses - as can be shown by using Newton's law of viscosity - proportional to $L$ and independent of the shear viscosity.

The present paper is confined to the second type of forces; forces associated with avalanche movements are generally excluded. Since applications are envisaged, the extreme values of the stresses are of especial interest because they have to serve as a basis for the design of structures. Because gravity is the only body force to consider, our forces are a function of the total snow depth and associated densities, that is to say of the water-equivalent of the snow cover. The maximum values of these quantities to be expected are monotonically increasing functions of the return period (the mean time interval in years within which a certain event reaches or exceeds a certain magnitude). For an optimum design of structures, the requirements of the structures have to meet the chosen return period. For our problems the most important functions are maximum snow depth and water-equivalent in relation to return period for different climatic regions. The best way to represent such data is to establish a distribution function for a reference sea-level and in addition an altitude dependence within a region. This must be done on the basis of continuous measurements and calculated with the methods used in the statistics of extremes. It will not be the object of this paper to describe these methods; the needed quantities will be assumed to be known.

\section{SNOW GOVER ON HORIZONTAL GROUND}

\section{I. State of stress and deformation}

The simplest case is snow cover with uniform thickness $D$ and a surface free of stress. One principal stress (and therefore as can generally be assumed also a principal strain-rate) is always perpendicular and the other two parallel to the ground. The boundary conditions are a stress-free surface and a vanishing settlement velocity on the ground.

If constant density and Newtonian behaviour are assumed, the following well-known results are obtained (Fig. I). The principal stresses $\sigma_{1}, \sigma_{2}$ and $\sigma_{3}$ become

$$
\sigma_{\mathrm{I}}=\sigma_{x}=-\gamma x \text {, }
$$

and

$$
\sigma_{2}=\sigma_{3}=\sigma_{y}=\sigma_{z}=\frac{\sigma_{x}}{m-\mathrm{I}},
$$

or written with the coefficient of pressure at rest $\zeta$

$$
\zeta=\frac{\sigma_{y}}{\sigma_{x}}=\frac{\mathrm{I}}{m-\mathrm{I}} .
$$

where $m$ is the viscous analogue of the cross-section number or the inverse of the viscous analogue of Poisson's ratio (i.e. the ratio of the longitudinal to the lateral rate of deformation in the uniaxial state of stress).

From this the magnitude of the settlement velocity $u$ is obtained as

$$
u=u_{0}\left(\mathrm{I}-\frac{x^{2}}{D^{2}}\right)
$$




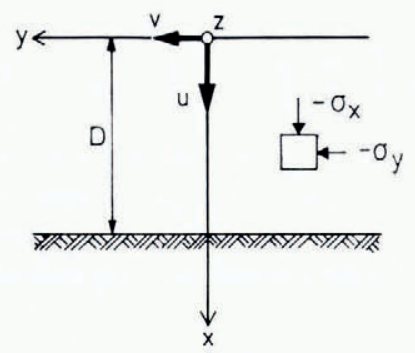

Fig. I. System of coordinates in the snow cover $x, y, z$ and associated velocities $u, v, w$ and stresses $\sigma_{x}, \sigma_{y}, \sigma_{z}$.

where

$$
u_{0}=\frac{\gamma(m-2)}{2 \mu(m-1)} \frac{D^{2}}{2},
$$

is the value at the surface $x=0 . \mu$ is the shear viscosity. For the stress at the ground $x=D$ we get

$$
\sigma_{x}=-\frac{2 \mu(m-1)}{m-2} \frac{2}{D} u_{0}=-\gamma D
$$

where $u_{0}$ and $D$ are the characteristic velocity and length respectively, the requirements of the creep number are fulfilled in Equations (8) and (9).*

If stresses are acting on the surface of the snow cover, e.g. a uniform pressure $p$ over the segment $-b \leqslant y \leqslant b$ of the boundary $x=0$ (Fig. 2), then the following stresses have to be superposed on those given by Equations (4) and (5) respectively:

$$
\begin{aligned}
\sigma_{x} & =-\frac{p}{2 \pi}\left[2 \alpha_{2}-2 \alpha_{1}-\left(\sin 2 \alpha_{2}-\sin 2 \alpha_{1}\right)\right], \\
\sigma_{y} & =-\frac{p}{2 \pi}\left[2 \alpha_{2}-2 \alpha_{1}+\left(\sin 2 \alpha_{2}-\sin 2 \alpha_{1}\right)\right], \\
\tau_{x y} & =\frac{p}{2 \pi}\left[\cos 2 \alpha_{2}-\cos 2 \alpha_{1}\right],
\end{aligned}
$$

where $\alpha_{1}$ and $\alpha_{2}$ are the angles in polar coordinates defining the position of the element under consideration from origins at $x=0, y=-b$ and $x=0, y=b$ respectively (Fig. 2).

These equations are derived for the two-dimensional case and for a linear-elastic semiinfinite solid and are analogously also valid for a Newtonian fluid. The example given in Figure 2 shows that the principal stresses are no longer perpendicular and parallel to the ground and that the perturbation is distributed over an increasing area accompanied by a reduction of the stress peaks.

According to an idea of Bucher (1948), Equation (7) can easily be generalized for an arbitrary snow cover which is subdivided into layers with constant density, viscosity and cross-section number. For a layer $\Delta D_{i}$ (Fig. 3) $x_{i-1} \leqslant x \leqslant x_{i}$ and the constants of the material denoted by an index $i$, the stress is

$$
\sigma_{x}=-\gamma_{i} x-\sum_{i}^{i-1} \gamma_{i} \Delta D_{i}
$$

\footnotetext{
* An arbitrary expression containing the cross-section number could be included in the creep number since the cross-section number is dimensionless. However because its influence depends on the state of stress, no general expression can be given.
} 
and the corresponding velocity

$$
u=\frac{m_{i}-2}{2 \mu_{i}\left(m_{i}-\mathrm{I}\right)}\left[\frac{\gamma_{i} x_{i}^{2}}{2}\left(\mathrm{I}-\frac{x^{2}}{x_{i}^{2}}\right)+\left(x_{i}-x\right) \sum_{\mathrm{I}}^{i-1} \gamma_{i} \Delta D_{i}\right]+u_{0 i} .
$$

The calculation of Equation (14) has to start with the lowermost layer where $u_{0} i$ vanishes.

For non-Newtonian behaviour Equation (14) remains valid if mean values of viscosity and cross-section number-corresponding to the mean stress and to the uniaxial state of deformation-are taken from a known constitutive equation.

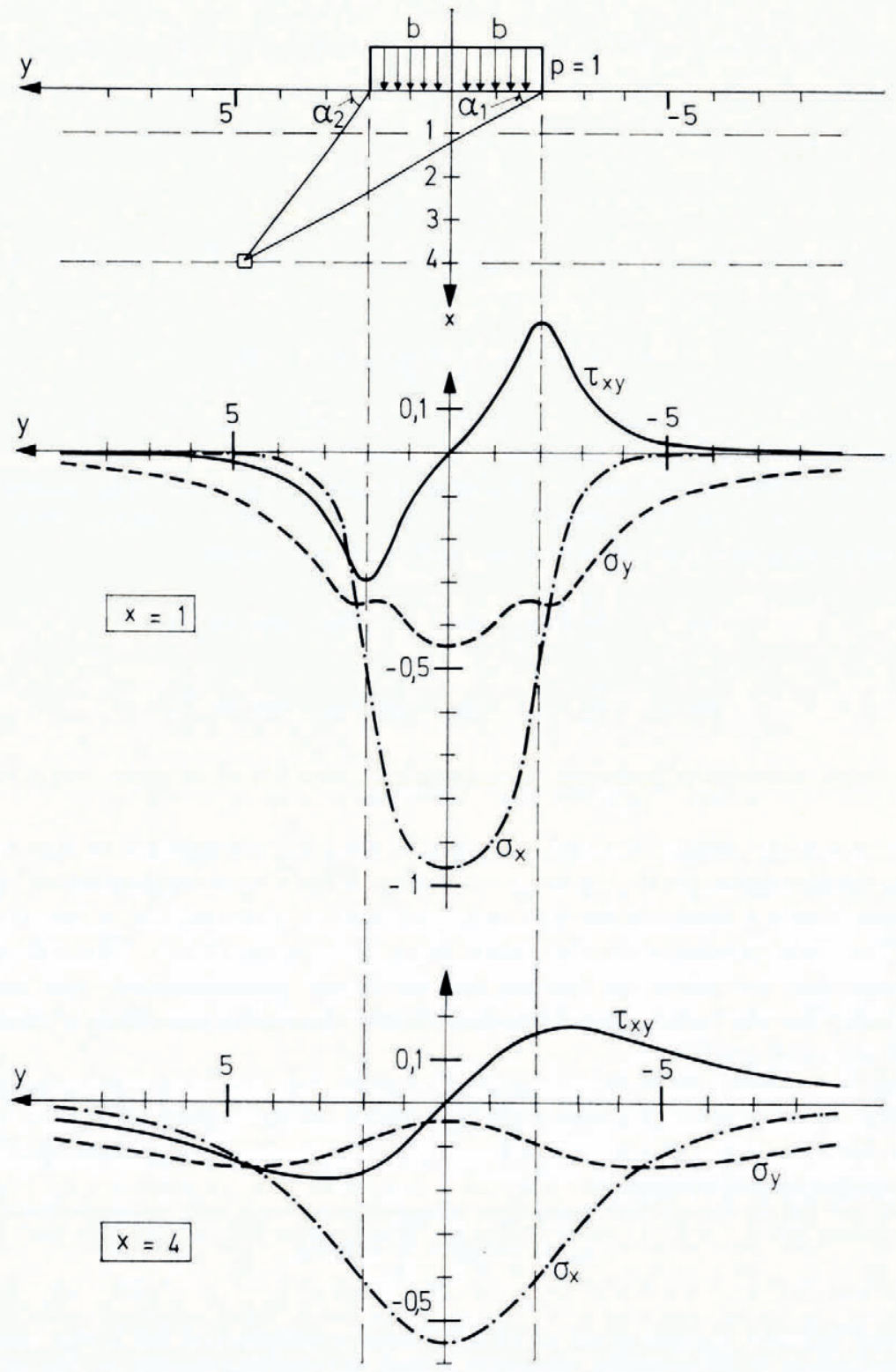

Fig. 2. Additional stresses in a horizontal snow cover with a uniform pressure p acting on its surface. 


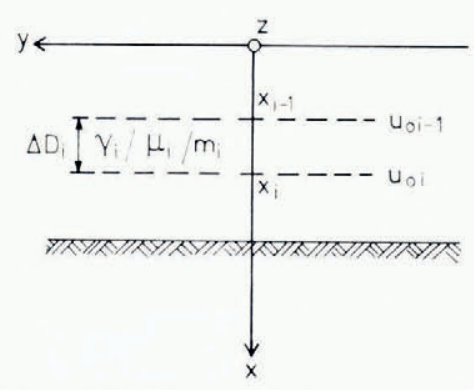

Fig. 3. Multi-layer model of the snow-pack.

\subsection{Normal stress on the ground}

For practical purposes, the most important force is the velocity-independent normal stress on the ground (snow load). It serves as a basis for the determination of snow loads on roofs.

Probably the most comprehensive investigations concerning this problem were made by the National Research Council of Canada (e.g. Allen, I956; Allen, r958; Allen and Turkstra, 1958; Lutes, I970; Schriever and others, [1975], etc.). Recently the International Organisation for Standardization (I974) (ISO) has elaborated a draft proposal for the snow loads on roofs, which seems to be in agreement with the Canadian results. It is stated that first of all the snow load on ground has to be known as a function of the return period, the altitude and the climatic region (see Section I). For examples see German standards (Deutsches Institut für Normung, 1975) and Martinec (1977). For design, a return period of 50 years is proposed, but using more than one could be foreseen, e.g. 5 years for an ordinary and 50 years for an extraordinary load, both of course with appropriate permissible stresses (i.e. higher ones for the longer return period). In perfectly calm weather, falling snow would cover roofs and the ground with a uniform blanket of snow, and the design snow load could be considered as a uniformly distributed load equal to the snow load on the ground. This case however is rare and is only observed in areas that are sheltered on all sides by high trees, buildings, etc. In most regions snowfalls are accompanied or followed by winds, which will redistribute the snow on the roof. The snow load on a roof $s$ is therefore defined as the product of the (undisturbed and representative) snow load on the ground $s_{\mathrm{g}}$ and a shape coefficient $\mu$. Also parameters such as the roof surface material, heating of the roof, etc., can be of importance, but are, due to lack of information, not included in the draft.

As an example of the ISO proposal, Figure 4 represents the shape coefficients of a biplanar roof. It demonstrates that the accumulated leeward drift load is larger than $s_{\mathrm{g}}$. On the other hand the sliding effect is taken into account for steep roofs $\left(\beta \geqslant 60^{\circ}\right)$. When the building is exposed to the winds on all sides, the ISO proposal allows a reduction of the snow load coefficients of $25 \%$ (e.g. $\mu_{1}=\mu_{2}=0.6$ for $\beta=0$ ). It seems important that this wind exposition must be guaranteed also in future and must not be altered by new buildings or trees. Two (rare) special cases may be added to the ISO draft. First, the already mentioned possibility of snowfall without wind. Here for flat roofs, i.e. without sliding effect, all coefficients should be set to unity. Secondly, extremely wind-exposed sites in high altitudes-e.g. at the top of a mountain - where the snow load may become independent of ground load and only be given by the mechanics of the air-snow mixture, i.e. the possibilities of snow accumulation in the flow pattern. Finally, an effect should be taken into account which is often observed but so far nowhere mentioned in standards, that is the possibility of snow deposits exceeding the ground plan of a roof, as a result of snow drift and creeping or creeping and gliding (movement at the roof-snow interface). At least a length of overhang of about the snow depth on the roof should generally be added to the load. In regions abundant with snow the 


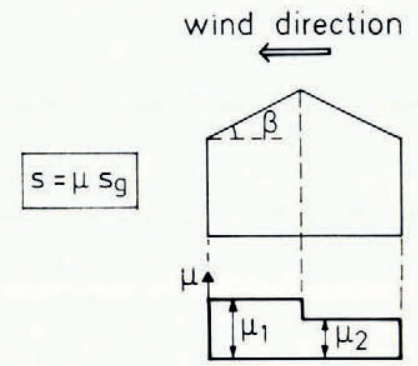

\begin{tabular}{|c|l|}
\hline $0^{\circ} \leq \beta \leq 15^{\circ}$ & $\mu_{1}=\mu_{2}=0,8$ \\
\hline $15^{\circ}<\beta<30^{\circ}$ & $\begin{array}{l}\text { linear interpo- } \\
\text { lation with } \beta\end{array}$ \\
\hline$\beta=30^{\circ}$ & $\mu_{1}=1,2 \mu_{2}=0,8$ \\
\hline $30^{\circ}<\beta<60^{\circ}$ & $\begin{array}{l}\text { linear interpo- } \\
\text { lation with } \beta\end{array}$ \\
\hline$\beta \geq 60^{\circ}$ & $\mu_{1}=\mu_{2}=0$ \\
\hline
\end{tabular}

Fig. 4. Snow load on a biplanar roof (according to the ISO draft).

overhang may be much larger. In extreme cases the overhanging snow joins up with the snow cover on the ground and causes a great increase in the load.

In forestry the snow load on trees is of some importance as a cause of damage. Only little data, especially from Japanese researchers, are available (see Wakabayashi, 1975 and therein mentioned literature). In this case snow load on the ground is only of minor importance for tree loads, whereas the type and shape of tree, the temperature of the air and the wind intensity seem to dominate the problem. Reported values of loads referred to the groundplane of a tree vary between 15 and $50 \mathrm{kp} \mathrm{m}^{-2}$.

\subsection{Stresses parallel to the ground}

From the viewpoint of applications, stresses parallel to the horizontal ground are less important than those described in the previous section, although sometimes the problem of horizontal loading of vertical walls of buildings or avalanche galleries arise. The problem is, however, more attractive for snow mechanics. In the following we confine consideration to a snow cover with uniform depth and a surface free of stress, i.e. to the pressure at rest, which is a basic feature of snow mechanics with close relations to the stress conditions in an inclined snow cover.

Assuming Newtonian behaviour, the following methods have been used for the determination of coefficient $\zeta$ of Equation (6):

(I) Direct measurement of the vertical and horizontal pressure, $\sigma_{x}$ and $\sigma_{y}$ respectively, under a uniaxial state of deformation.

(2) Measurement of the cross-section number under a uniaxial state of stress and calculation of $\zeta$ by Equation (6).

(3) Measurement of the creep angle $\beta$, i.e. the angle between the velocity vector of a snow particle and the direction parallel to ground in the neutral zone (vanishing gradients parallel to ground) of a sloping snow cover. In terms of the slope angle $\psi$ we get 


$$
\tan \beta=\frac{\mathrm{I}}{\tan \psi} \frac{m-2}{2(m-\mathrm{I})},
$$

which for $\psi=45^{\circ}$ becomes the standard value

$$
\tan \beta_{45^{\circ}}=\frac{m-2}{2(m-1)},
$$

and with this

$$
\zeta=\mathrm{I}-2 \tan \beta_{45^{\circ}}
$$

or

$$
m=2 \frac{\mathrm{I}-\tan \beta_{45^{\circ}}}{\mathrm{I}-2 \tan \beta_{45^{\circ}}} .
$$

(4) Compression of thin sections and measurement of the longitudinal and lateral displacement of snow particles. Since this is obviously a two-dimensional state of deformation, the ratio of the longitudinal and lateral displacement obtained as to be corrected by the addition of unity.

Continual assumption of Newtonian behaviour leads to the idea that the cross-section number depends on density and structure of snow. The influence of temperature is certainly less, because $m$ is a ratio of rates of deformation where viscosity - to which temperature dependence is normally attributed-does not appear. We write therefore

$$
m_{(\gamma, \mathrm{s})}=m_{(\gamma)} \cdot m_{\left(\mathbf{s}, \gamma_{0}\right)},
$$

where the parameter $\gamma$ means the influence of density and $s$ that of the structure; $\gamma_{0}$ is a reference density. If $m_{(\gamma)}$ is known, the influence of structure alone becomes

when $m_{(\mathrm{s}, \gamma)}$ is a measured value.

$$
m_{\left(\mathbf{s}, \gamma_{0}\right)}=\frac{m_{\left(\gamma_{0}\right)}}{m_{(\gamma)}} m_{(\mathrm{s}, \gamma)},
$$

Haefeli (1942[a], [b], I966) used the third method as described above. His results are represented in Figure 5. He derived a density function

$$
m_{(\gamma)}=\frac{\gamma / \gamma_{i}+0.9}{\gamma / \gamma_{i}-0 . \mathrm{I}}, \quad \text { for } \mathrm{I} 80 \mathrm{kp} \mathrm{m}^{-3}<\gamma<740 \mathrm{kp} \mathrm{m}^{-3}
$$

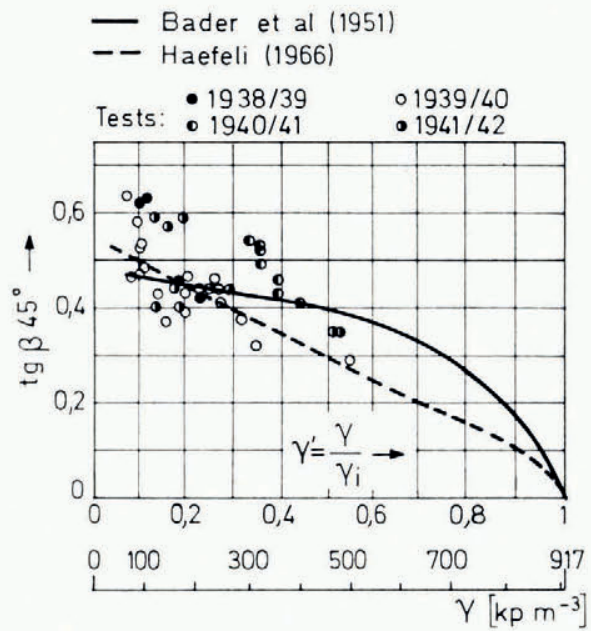

Fig. 5. Haefeli's test results for the determination of $\tan \beta_{45^{\circ}}$ and the pressure coefficient at rest. 
with $\gamma_{i}$ being the density of ice. The scatter of the results must be attributed to the influence of structure. Haefeli's results are mainly valid for the domain of low densities and stresses.

Bader and others (I95I) used the second method. The results (Fig. 6) can be represented by a density function (with $\gamma$ in $\mathrm{kp} \mathrm{m}^{-3}$ ):

$$
m_{(\gamma)}=\frac{\mathrm{I} .4^{8}}{\mathrm{IO}^{-3} \gamma}\left[\mathrm{I}-\left(0.80 \times 10^{-3}\right) \gamma\right]\left[\mathrm{I}+\left(3.87 \times \mathrm{IO}^{-3}\right) \gamma\right],
$$

and are valid for the domain of higher densities and probably (though not explicitly indicated) higher stresses. Again the scatter of the results must be attributed to the influence of structure.

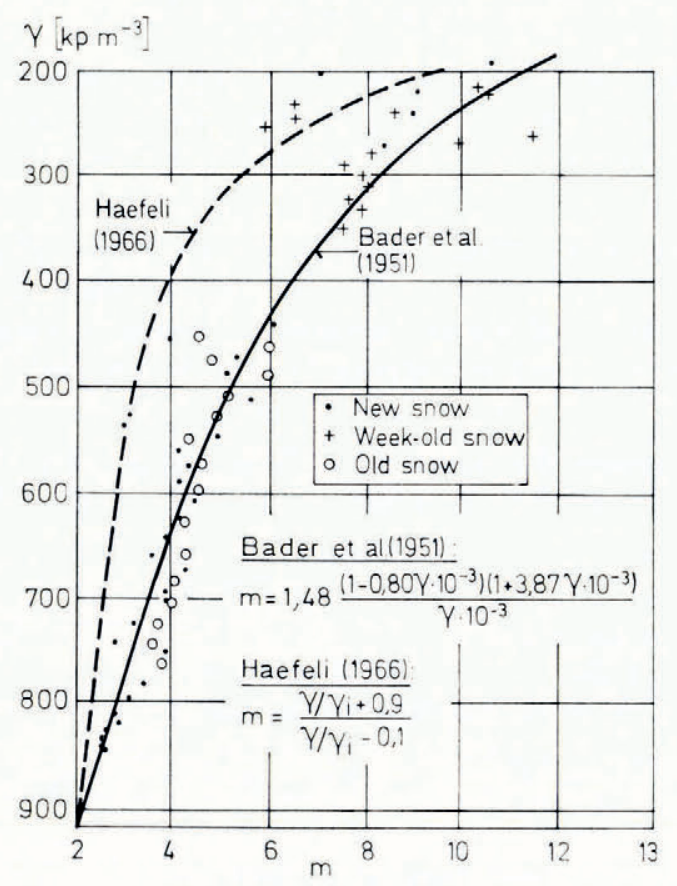

Fig. 6. Measurements of the cross-section number by Bader and others (I95I).

Comparison of Equations (2I) and (22) with a compilation of results by Roch (I948) represented in Figure 7, gives the impression that these density functions cover the main domain of measured cross-section numbers, except the results of the tensile tests, which seem to be too high because, roughly speaking, snow under uniaxial tensile stresses does not change its volume $(m=2)$.

When the assumption of Newtonian behaviour is abandoned, the cross-section number becomes additionally a function of the longitudinal stress $\sigma_{x}$ and Equations (5) and (6) are no longer valid. In this case obviously only the first of the above-mentioned methods will furnish reliable results. Landauer (1957) first recognized that the cross-section numbers resulting from the second method and the use of Equation (6) generally over-estimates the real coefficients $\zeta$. His results using method $\mathrm{I}$ and 2 are represented in Figure 8. It seems however, that his $m$-values for the uniaxial state of deformation are too large, probably as a consequence of his measuring method (friction on the side walls). More reasonable data from the first method were obtained by de Quervain (1966) and Klausegger (unpublished data), 


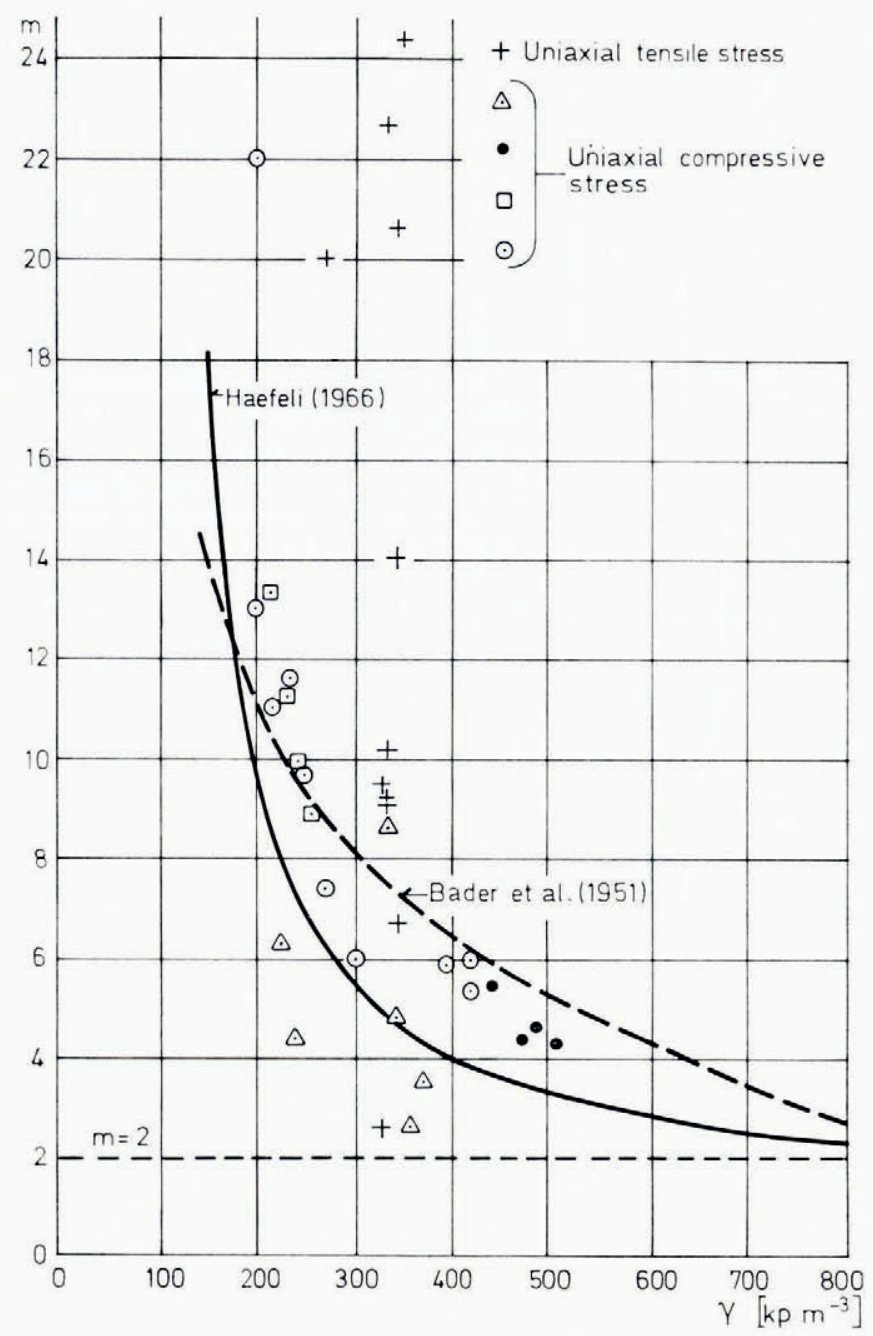

Fig. 7. Compilation of cross-section numbers by Roch $\left(194^{8}\right)$.

who made measurements in the natural snow cover by means of electrical pressure plates (Fig. 8). The data below Haefeli's function originate from low stresses in shallow snow and have no significance. The range of variation of $m$ with $\sigma_{x}$ is demonstrated in Figure 8 by results of laboratory tests (Salm, in press) under uniaxial deformation with snow of uniform structure and fitted with a non-Newtonian constitutive equation.

As an example for the fourth method, Yosida's (1963) data are plotted in Figure 8. With the correction recommended by the author - to add unity to the measured ratio of deformation - the points are shifted into the range of both density functions.

To conclude this section, an attempt will be made to estimate the relative importance of the two factors on the right-hand side of Equation (19). To do this, the density function $m_{(\gamma)}$ is assumed to be given by the average of the values given by Equations (2I) and (22). With Equation (20) and a reference density of $\gamma_{0}=350 \mathrm{kp} \mathrm{m}^{-3}$ the structure-dependent magnitude of $m_{\left(\mathrm{s}, \gamma_{0}\right)}$ is calculated from experimental $m_{(\mathrm{s}, \gamma)}$. Then the coefficient of pressure at rest $\zeta$ is 


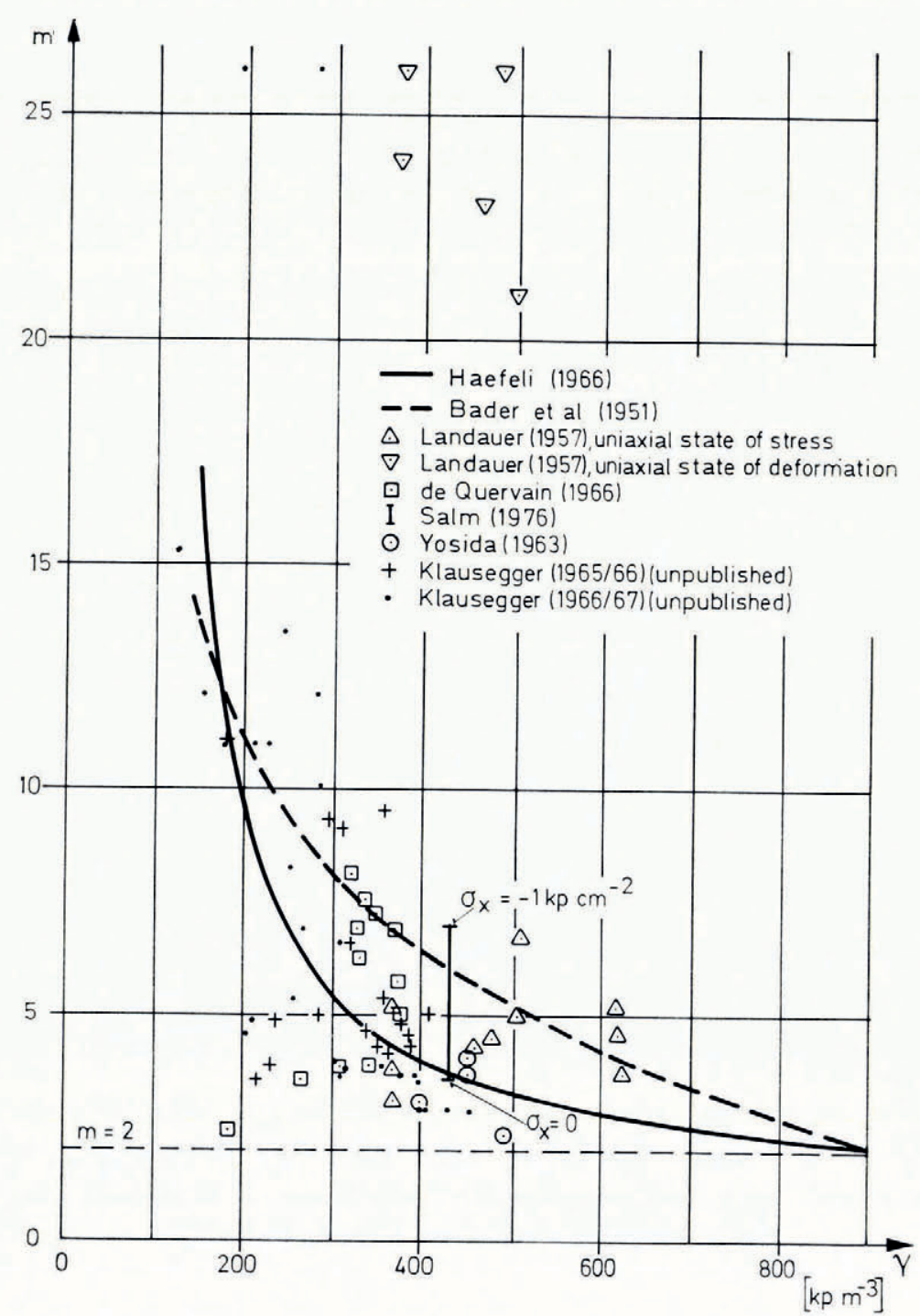

Fig. 8. Measurement of the cross-section number. Comparison of results using different testing methods.

determined by Equation (6), which is not exactly correct because of the non-Newtonian behaviour. The error involved can be assessed in Figure 9, a plot of $\zeta$ versus $\sigma_{x}$, where the results of Salm (in press) with snow of uniform structure fitted on the basis of a non-Newtonian constitutive equation are shown. The lower curve represents the directly measured $\zeta$. The dashed curve was obtained from (stress-dependent) cross-section numbers resulting from the uniaxial-state of stress and $\zeta$ calculated using Equation (6). Both curves decrease with increasing stress and their difference is not dramatic so that Equation (6) may be used for applied problems. In Figure 9 available data with known density and stress intensity are collected, the only remaining free parameter is therefore the structure. The high scattering - enlarged by errors because of the measuring method (see, e.g. the remarks above on 


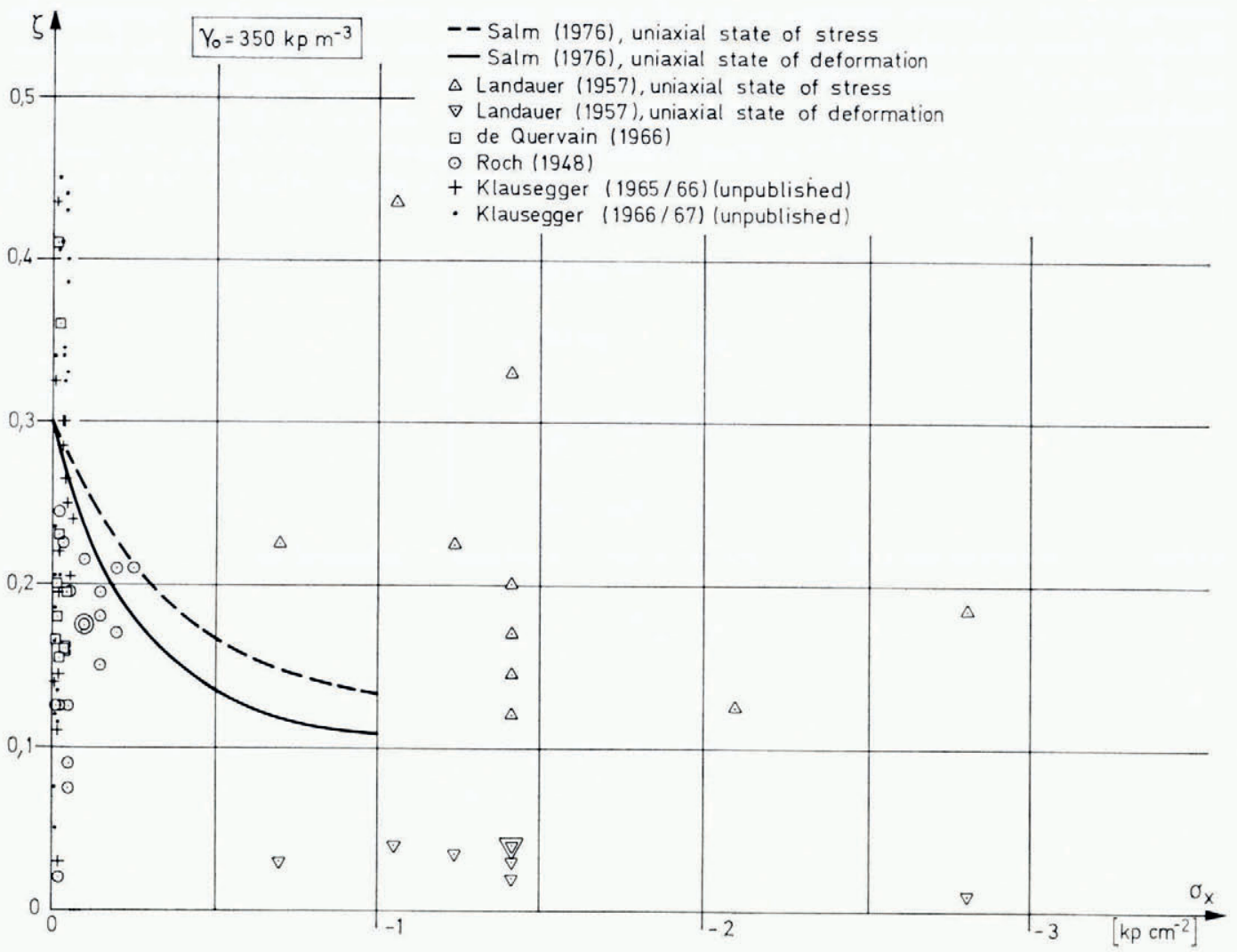

Fig. 9. Influence of stress on the cross-section number (non-Newtonian behaviour).

Landauer's and de Quervain's results) and by the use of Equation (6)-demonstrates emphatically the dominating influence of $m_{\left(\mathrm{s}, \gamma_{0}\right)}$. Future research should be directed to a quantitative understanding of it.

The conclusion is, that for a rough estimate of stresses parallel to the ground-in many cases sufficient for practical applications-Equation (6) together with Haefeli's function, Equation (2 I), and Bader's, Equation (22) may be used for compression. For tension the value $m=2$ applies approximately.

The problem of the cross-section number was treated in some detail because it is-besides density - the only mechanical parameter affecting the pressure on rigid obstacles directly, as will be shown in the following sections.

\section{SNOW Gover on SLOPES}

\section{I. State of stress and deformation}

The simplest case is the infinite snow cover of constant thickness $D$, inclined with a constant angle $\psi$ and having a surface free of stress. The so-called "neutral zone" is defined by the disappearance of all gradients (including characteristics of the material and the snowground interface conditions) respective to the $y$-axis parallel to the ground (the same system of coordinates as in Figure $\mathrm{I}$ will be used, with the $y$ direction positive downward). If coincidence of the principal stresses and rates of strain is assumed, the principal directions can be 
determined by a known velocity vector of a snow particle (creep angle $\beta$ ) as proposed by Haefeli (Bader and others, 1939).* The boundary conditions are a stress-free surface and, on the ground, vanishing velocity $u$ perpendicular to the ground and generally a nonvanishing velocity $v_{\mathrm{g}}$ parallel to it. The latter is called the "gliding velocity".

If constant density and Newtonian behaviour are assumed, the following well-known results are obtained (same symbols as in Figure I). The stresses related to the system of coordinates become

$$
\left.\begin{array}{rl}
\sigma_{x} & =-\gamma x \cos \psi, \\
\tau_{x y} & =-\gamma x \sin \psi, \\
\sigma_{y} & =\sigma_{z}=\frac{\sigma_{x}}{m-\mathrm{I}}, \\
\tau_{y z} & =\tau_{x z}=0 .
\end{array}\right\}
$$

From this, the component of the velocity in the $x$-direction is obtained as

$$
u=u_{\mathrm{o}}\left(\mathrm{I}-\frac{x^{2}}{D^{2}}\right),
$$

where

$$
u_{0}=\gamma \cos \psi \frac{m-2}{2 \mu(m-1)} \frac{D^{2}}{2},
$$

is its value at the surface $x=0$.

The component in $y$-direction becomes

$$
v=v_{0}\left(\mathrm{I}-\frac{x^{2}}{D^{2}}\right)+v_{\mathrm{g}}
$$

where $v_{0}$ is its value at the surface $x=0$

$$
v_{0}=\gamma \sin \psi \frac{\mathrm{I}}{\mu} \frac{D^{2}}{2}
$$

The ratio of $u$ and $v$ for $v_{\mathrm{g}}=\mathrm{o}$ is the tangent of the creep angle $\beta$, already given in Equation (I5). It is constant over $D$.

According to Haefeli ( $194^{2}[\mathrm{a}]$ ) the principal stresses can be expressed in terms of the slope and creep angle:

$$
\left.\begin{array}{l}
\sigma_{1}=-\gamma x\left[\cos \psi+\sin \psi \cot \left(45^{\circ}+\frac{\beta}{2}\right)\right], \\
\sigma_{2}=-\gamma x\left[\cos \psi-\sin \psi \tan \left(45^{\circ}+\frac{\beta}{2}\right)\right], \\
\sigma_{3}=-\gamma x \frac{2}{m}[\cos \psi-\sin \psi \tan \beta]=-\gamma x \frac{\cos \psi}{m-\mathrm{I}} .
\end{array}\right\}
$$

* The general deduction of the creep angle by Perla $(1971,1972)$ is essentially nothing else than a consequence of the same assumption, and therefore independent of constitutive equations. 
Haefeli (I966) introduced a "critical slope angle" $\psi_{0}$, for which $\sigma_{2}=0$. Its value is reached if

$$
\tan \psi_{0}=+\left(\frac{\mathrm{I}}{m-\mathrm{I}}\right)^{\frac{1}{2}},
$$

for higher $\psi$ the second principal stress becomes tensile.

If the surface is not free of stress, e.g. if a force of the magnitude $R$ at an angle $\delta$ to the surface is acting on the boundary $x=0$ (Fig. 1o) then the following stresses have to be superposed on those given by Equation (23):

$$
\begin{aligned}
\sigma_{x} & =\sigma_{\mathrm{r}} \sin ^{2} \alpha, \\
\sigma_{y} & =\sigma_{\mathrm{r}} \cos ^{2} \alpha, \\
\tau_{x y} & =\sigma_{\mathrm{r}} \sin \alpha \cos \alpha,
\end{aligned}
$$
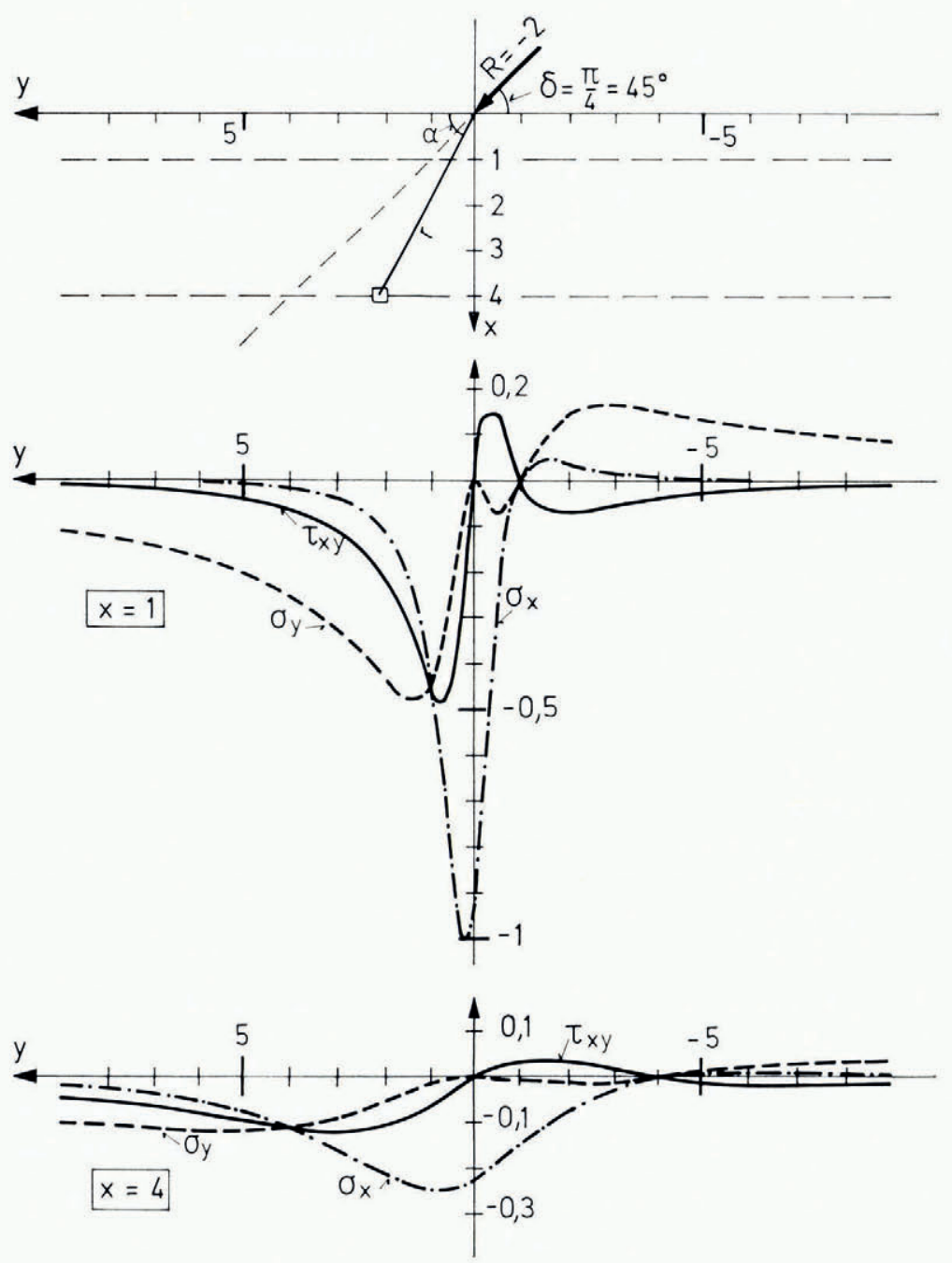

Fig. 10. Additional stresses in an inclined snow-pack by a single force. 
where the radial stress is

$$
\sigma_{\mathrm{r}}=\frac{2 R}{\pi r}(\alpha-\delta)
$$

The above equations are derived for the two-dimensional case and for a linear-elastic semiinfinite solid and are analogously also valid for a Newtonian fluid. The example given in Figure Io shows a rapid distribution of the perturbation over an increasing area accompanied by a reduction of the stress peaks.

As with snow cover on horizontal ground, Equations (24) and (26) can be easily generalized for an arbitrary snow cover if this is subdivided into layers with constant density, viscosity and cross-section number. For a layer $\Delta D_{i}$ (same notation as in Figure 3 ) $x_{i-1} \leqslant x \leqslant x_{i}$ and with constants of the material denoted by an index $i$, the stresses are

$$
\begin{gathered}
\sigma_{x}=-\gamma_{i} x \cos \psi-\sum_{\mathbf{I}}^{i-\mathbf{I}} \gamma_{i} \Delta D_{i} \cos \psi, \\
\tau_{x y}=-\gamma_{i} x \sin \psi-\sum_{\mathbf{I}}^{i-\mathbf{I}} \gamma_{i} \Delta D_{i} \sin \psi,
\end{gathered}
$$

and the corresponding velocities

$$
\begin{aligned}
u & =\frac{m_{i}-2}{2 \mu_{i}\left(m_{i}-\mathrm{I}\right)} \cos \psi\left[\frac{\gamma_{i} x_{i}^{2}}{2}\left(\mathrm{I}-\frac{x^{2}}{x_{i}^{2}}\right)+\left(x_{i}-x\right) \sum_{\mathrm{I}}^{i-1} \gamma_{i} \Delta D_{i}\right]+u_{0}, \\
v & =\frac{\sin \psi}{\mu_{i}}\left[\frac{\gamma_{i} x_{i}^{2}}{2}\left(\mathrm{I}-\frac{x^{2}}{x_{i}^{2}}\right)+\left(x_{i}-x\right) \sum_{\mathrm{I}}^{i-1} \gamma_{i} \Delta D_{i}\right]+v_{0} .
\end{aligned}
$$

The calculation of Equations (36) and (37) has to start with the lowermost layer where $u_{0 i}$ is zero and the gliding velocity $v_{\mathrm{g}}$ must be known.

For non-Newtonian behaviour Equations (36) and (37) remain valid if mean values of viscosity and cross-section number - corresponding to mean stresses and to the two-dimensional state of deformation - are taken from a known constitutive equation.

No supplementary remarks have to be added for stresses on the ground in the neutral zone; the resultant stresses remain the same as in the horizontal snow cover and consist of a normal and shear stress (although the present Swiss standards (Schweizerischer Ingenieurund Architekten-Verein, 1970) neglect the shear stress of the snow load on an inclined roof if "sliding off is not prevented").

\subsection{Snow gliding}

With regard to applications, snow gliding is an important component of the motion in the seasonal snow cover. Several mechanisms have been proposed and it seems that in nature several are competing. The movement occurs when the temperature at the ground, i.e. in the snow-ground interface, is at or above the melting point of snow.

The parameters influencing the magnitude of the motion can be subdivided into those

- originating from snow (temperature, water content of the boundary layer, magnitude and state of stress), and

- originating from ground, i.e. characteristics or constants of the terrain independent of the special weather and snow conditions in one winter (slope angle, altitude, roughness and water permeability of the ground, kind of surface of the material forming the ground).

An interrelation between varying and constant parameters exists through the actual temperature of the ground at the time of the first snowfall (determined by weather and ground elements). 
Haefeli (Bader and others, I939) did experimental work to investigate how the sliding velocity of a snow sample depends on the magnitude of shear and normal stress with different temperatures. As material for the ground he used a flat glass plate. He found that after a small displacement $(<\mathrm{I} \mathrm{mm})$ a constant sliding velocity was obtained for each slope and load. The representation of his results became obscure because he attributed his observations to a Coulomb type of friction (stress-independent cohesion plus a term proportional to the normal stress). If however his data are fitted by a relation

$$
\tau_{x y}=a_{0}\left(\sigma_{x}, t\right)+a_{1}\left(\sigma_{x}, t\right) \cdot v_{\mathrm{g}},
$$

where $a_{0}$ and $a_{\mathrm{I}}$ are functions of the normal stress $\sigma_{x}$ and the temperature $t$, surprisingly simple correlations can be found. From Figure I I, the tests for which were performed with a constant temperature $t=\mathrm{o}^{\circ} \mathrm{C}$, it follows that

and

$$
\left.\begin{array}{l}
a_{0}=c=\text { constant, } \\
a_{\mathrm{I}}=\frac{\mu_{\mathrm{w}}}{\delta\left(\sigma_{x}\right)},
\end{array}\right\}
$$

$\mu_{\mathrm{w}}$ being the viscosity of water $\left(\right.$ at $t=0^{\circ} \mathrm{C}$ ) and $\delta$ the thickness of the shear boundary layer, assumed to consist of water. $\delta$ linearly increases with the magnitude of the normal stress (Fig. I I). The conclusion can be drawn that as far as snow participates in the gliding process on a surface without macroscopic roughness, a stress-independent cohesion and a Newtonian viscosity seem to create shear stresses.

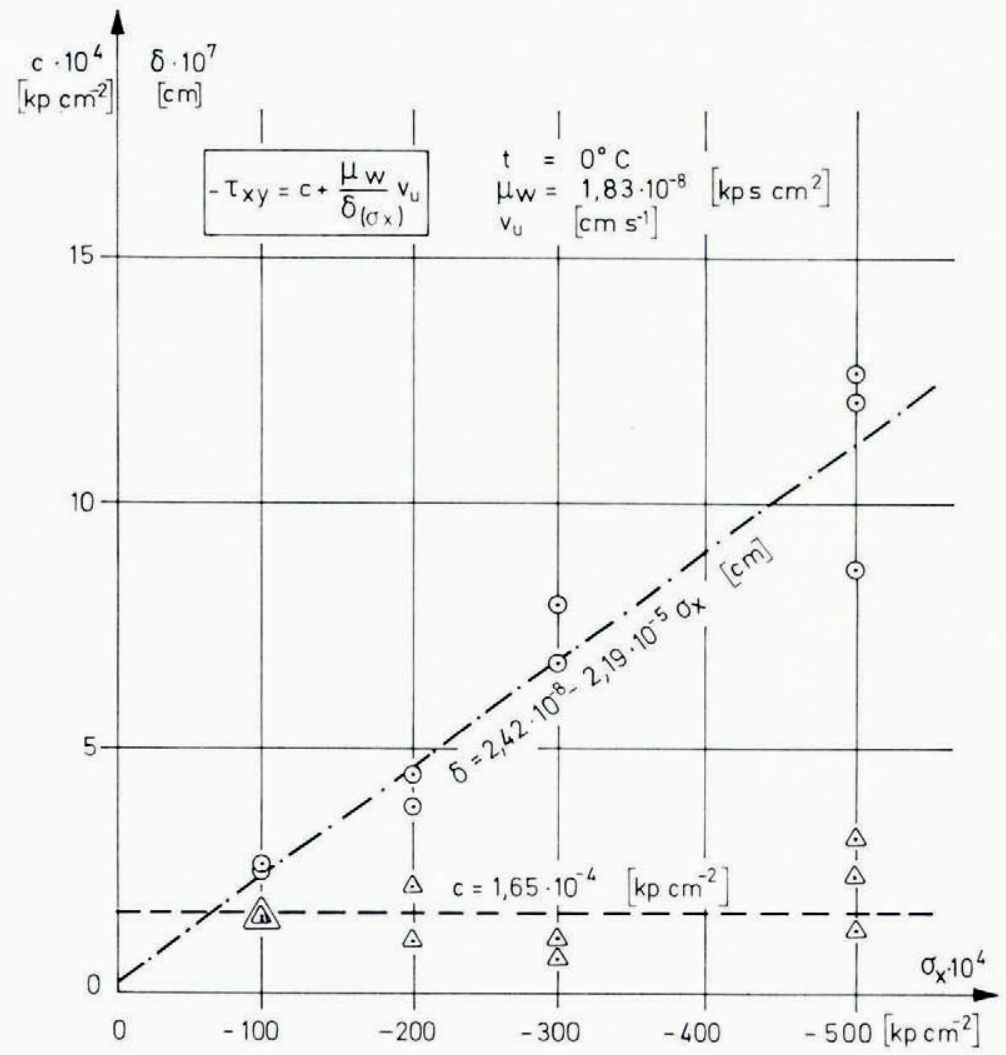

Fig. II. Reinterpretation of Haefeli's (Bader and others, 1939) tests on snow gliding on a flat glass plate. 
Haefeli found furthermore a profound effect of the transition from a wet to a dry interface upon the frictional characteristics. By definition this is no longer gliding but a creep mechanism within the snow structure which can be treated by Equation (37).

The parameters of Equations (38) and (39) should be investigated for different surfaces without macroscopic roughness (e.g. a smooth grass surface). In a steadily gliding snow-pack, shear stresses given by Equation ( $\left.3^{8}\right)$ equilibrate the value of the tangential stress (Equation (35)) on the ground. As on Haefeli's glass plate, stresses given by Equation (38) are one order of magnitude smaller than the normal stresses, equilibrium is possible only with very small slope angles. But material with higher microscopic roughness than glass would probably exhibit also higher shear stresses as given by Equation ( $\left.3^{8}\right)$.

Bucher (1948) states that glide velocity is determined by snow viscosity, hence the actual velocity profile always has to become zero at the ground, maybe in a very small snow layer. He admitted non-zero values only in the case when the topmost layer of the ground itself is in motion, becoming viscous by water infiltration. This is true for creeping given by Equation (37), but not for gliding.

In contradiction to Equations $\left(3^{8}\right)$ and (39) in der Gand and Zupančič (1966) proposed a shear stress composed of dry friction (proportional to $\sigma_{x}$ ) and Newtonian viscous friction (proportional to $v_{\mathrm{g}}$, with constant $\delta$ ). They found $\delta=0.8 \mathrm{~cm}$, whereas the re-examination of Haefeli's test furnishes $\delta \approx 1_{10}^{-6} \mathrm{~cm}$, which demonstrates again that this would be a creep mechanism.

Brown and others (1973) discussed glide as a motion between materials with very different hardness. In such a case gliding is initiated by shear failure in the softer material (snow), and therefore is associated with the shearing capacity of snow. Healing may also happen. Thus a continuous process of fracture and healing - producing a steady speed-is expected. After a certain fracture, the shear stresses in the interface are assumed to be proportional to the normal stress (dry friction).

A realistic glide model has to include the macroscopic roughnesses of the ground, i.e. amplitudes of the unevenness of at least several snow-grain diameters. The shear stresses of the weight of the snow pack are then additionally supported by these roughness obstacles. McClung ([1975], unpublished) considered this important aspect of gliding. Unlike Brown and others (1973) he did not think that fractures actually occur-which is probably true for most cases, because it appears generally unlikely that the necessary critical rate of deformation can be reached (Salm, I97I) - he has the idea that snow creeps around the obstacles. The basis of his considerations are results of investigations about the sliding of temperate glaciers over their beds (Nye, 1969, and others). The snow is modelled by an incompressible Newtonian fluid and shear stresses according to Equation (38) are neglected. A simple sine wave is assumed to model the ground roughness (general solutions may be obtained by a superposition rule). The influence of regelation is also discussed, but found to play a very small role if any. From this the average shear stress becomes

$$
\tau_{x y}=\frac{\mu}{d^{\prime}} v_{\mathrm{g}}
$$

$d^{\prime}$ is termed the "stagnation depth" (Fig. I2). It is an apparent thickness of a boundary layer and can be expressed as

$$
d^{\prime}=\frac{\mathrm{I}}{(2 \pi)^{3}}\left(\frac{\lambda_{0}}{A}\right)^{2} \lambda_{0}
$$

where $\lambda_{0}$ is the wavelength and $A$ the amplitude of the bed topography. $\mu$ means the (constant) viscosity of the lowermost snow layer of thickness $\Delta D$ (order of magnitude of $A$ ). An interesting feature of the stagnation depth is its dependence on the ratio of the wavelength and amplitude only, and not on the amplitude itself. This means for applications-e.g. the artificial reduction 


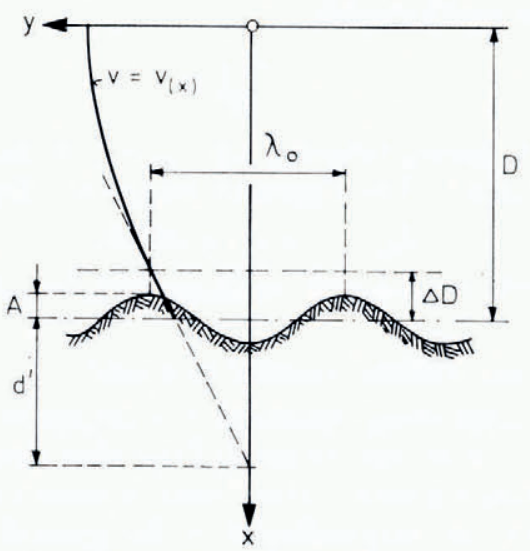

Fig. 12. Definition of the stagnation depth for an arbitrary velocity profile of the snow-pack. The ground is represented by a sine function.

of gliding in areas with supporting structures - that one has to make the wavelength as short as possible, the amplitude being of minor importance. (Limited by structural possibilities, e.g. minimum dimensions of earth terraces.)

For direct measurements of the stagnation depth, as performed by McClung (unpublished), two remarks have to be made. The depth is strictly speaking defined by the tangent line on the velocity profile of the lowermost layer as shown in Figure 12. Furthermore the tangent line on the displacement profile (e.g. sawdust column) may be misleading because of the variable gliding velocity with time as measured by, e.g. in der Gand and Zupančič (1966) or McClung (unpublished).

A superposition of the pure glide mechanism (Equations (38) and (39)) on the creep mechanism (Equations (40) and (4I)) yields a general glide law when in Equation (40) the apparent quantities

$$
\tau_{x y \text { ap }}=\tau_{x y}-c,
$$

and

$$
d_{\mathrm{ap}}{ }^{\prime}=\frac{d^{\prime}}{\mathrm{I}+\frac{\mu_{\mathrm{w}}}{\mu} \frac{d^{\prime}}{\delta}} .
$$

are introduced. McClung (unpublished) assumed Equation (42) for the effect of interdigitation caused by the vegetation. For $\mu$ he proposed furthermore to take a stress-dependent viscosity. In the case of higher microscopic roughness than that of glass, $\mu_{\mathrm{w}}$ probably becomes larger than the viscosity of water.

In Switzerland, field-test data have resulted in an empirical classification of gliding with respect to slope aspect and roughness characteristics (Switzerland. Eidg. Institut für Schneeund Lawinenforschung, 1968). This classification is understood as dependent on "terrain constants" under extreme snow conditions. Gliding is expressed with the parameter

$$
\mathcal{N}=\sqrt{ }\left(\mathbf{I}+3^{n}\right),
$$

known as the "glide factor", where $n$ is the relative glide velocity (Haefeli, 1948)

$$
n=\frac{v_{\mathrm{g}}}{v_{\mathrm{o}}},
$$


and becomes for a triangular creep profile

$$
n=\frac{d_{\mathrm{ap}}^{\prime}}{D}
$$

For practical applications $\mathcal{N}$ varies between 1.2 (aspect to north, rough terrain) and 3.2 (aspect to south, smooth terrain). The apparent stagnation depth therefore varies between

$$
d_{\mathrm{ap}}{ }^{\prime}=(0.15-3.08) D \text {. }
$$

McClung's data (unpublished) are near the minimum of this range.

\subsection{Interruption of the gliding and creeping movement by a wall}

In avalanche control by supporting structures, the structures have to be strong enough to withstand the snow forces due to the interruption of the glide and creep velocities. Commonly the problem is formulated in such a way that the state of stress and deformation in the neutral zone is perturbed by a rigid plane perpendicular to the ground and to the fall line and over the whole thickness of the snow cover. The length of this supporting plane across the slope may be confined (three-dimensional problem) or unconfined (two-dimensional problem). The stresses exerted on this plane are a function of the state of the snow cover in the neutral zone. In a Newtonian fluid the creep number $(C r)$ expresses the stresses being linearly dependent on a characteristic length, e.g. the thickness $D$. In the two-dimensional problem, forces result from an integration over $D$, are therefore proportional to the square of $D$ and analogously in the tridimensional problem proportional to the third power of $D$.

The first attempts to calculate snow forces on supporting structures were made by considering a snow block lying between two barriers and with dry friction resistance on the ground. This model is generally unrealistic because of the linear increase of snow pressure with the slope distance between the two structures. Haefeli (Bader and others, I939) recognized first the limitation of the zone within which additional compressive stresses are created and on the other hand shear stresses are reduced toward the obstacle. In view of this he introduced the back-pressure zone $y_{\mathrm{b}}$

$$
y_{\mathrm{b}}=-H\left[\frac{2}{\tan \beta_{45^{\circ}}}\left(\mathrm{I}+3^{n}\right)\right]^{\frac{1}{2}},
$$

where $H=D \cos ^{-1} \psi$ is the vertical snow depth. With an approximate value of $\tan \beta_{45^{\circ}}=0.3^{2}$ (corresponding to $\gamma \approx 400 \mathrm{kp} \mathrm{m}^{-3}$ ) the formula

$$
y_{\mathrm{b}} \approx-2.5 H\left(\mathrm{r}+3^{n}\right)^{\frac{1}{2}}=-2.5 H \mathcal{N},
$$

is obtained as a rough approximation (Haefeli, I948). The back-pressure zone-the practical effective range of a supporting structure up the slope-is the basic concept of Haefeli's snowforce calculation. He assumed a triangular creep profile (including gliding) and also took the pressure at rest-the remaining force for $\psi=0$-into consideration.

His final formulation of the resultant snow pressure per unit length across the slope, on a rigid wall is (Haefeli, 1948)

$$
S_{\mathrm{N}^{\prime}}=\frac{\gamma}{2} H^{2}\left[\left(\mathrm{I}-2 \tan \beta_{45^{\circ}}\right) \cos ^{3} \psi+\frac{\mathrm{I}}{3}\left(\frac{2}{\tan \beta_{45^{\circ}}}\right)^{\frac{1}{2}} \sin 2 \psi\left(\mathrm{I}+3^{n}\right)^{\frac{1}{2}}\right] .
$$

The distribution of the creep pressure (second term in the square brackets) is uniform over $H$, whereas the pressure at rest (first term in the square brackets) decreases linearly to the snow surface.

$S_{\mathrm{N}}{ }^{\prime}$ becomes for $\psi=\mathrm{o}$ the integrated value of Equation (5). Taking again $\tan \beta_{45^{\circ}}=0.3^{2}$, the approximation

$$
S_{\mathrm{N}^{\prime}} \approx \frac{\gamma}{2} H^{2} \Phi\left(\mathrm{I}+3^{n}\right)^{\frac{1}{2}}
$$


is obtained. For $30^{\circ} \leqslant \psi \leqslant 50^{\circ} \Phi$ varies only slightly around 0.95 . As the pressure at rest does not depend on the gliding process, Equation $(50)$ is not exactly valid. The above formula has proved to be in fairly good accordance with measurements and even with latest theoretical investigations, although some of Haefeli's assumptions cannot be completely justified (Salm, I96o).

When the wall is rough, the settlement $u$ is hindered because of the adhesion of snow on the wall, a force component parallel to the wall $S_{\mathrm{Q}}{ }^{\prime}$ develops. In analogy to Equation (I5) Haefeli (I948) takes for the angle $\epsilon$ between the resultant force and $S_{\mathrm{N}^{\prime}}$

$$
\tan \epsilon=\frac{S_{\mathrm{Q}^{\prime}}}{S_{\mathrm{N}^{\prime}}}=\frac{a}{\tan \psi},
$$

where $a$ is a constant to be found by field tests. The relation is established for pressures without gliding, if however gliding occurs $S_{Q^{\prime}}$ approximately does not change its value. This is the reason that in the Swiss guidelines (Switzerland. Eidg. Institut für Schnee- und Lawinenforschung, I968) $a$ is divided by the glide factor $\mathcal{N}$, occurring in Equations (49) and (50)

$$
\tan \epsilon=\frac{a}{\mathcal{N} \tan \psi} .
$$

Measurements showed a variation $0.2 \leqslant a \leqslant 0.5$, the lower value associated with dense and the higher with loose snow. Bucher ( $194^{8}$ ) made an attempt to calculate the snow forces by assuming Newtonian behaviour. The correct constitutive equation furnishes the following relations for plane strain (Fig. I):

$$
\begin{aligned}
\sigma_{z} & =\frac{\mathrm{I}}{m}\left(\sigma_{x}+\sigma_{y}\right), \\
\frac{\partial u}{\partial x} & =\frac{\mathbf{I}}{\mu} \frac{m-\mathbf{I}}{2 m}\left(\sigma_{x}-\frac{\sigma_{y}}{m-\mathrm{I}}\right), \\
\frac{\partial v}{\partial y} & =\frac{\mathbf{I}}{\mu} \frac{m-\mathbf{I}}{2 m}\left(\sigma_{y}-\frac{\sigma_{x}}{m-\mathrm{I}}\right), \\
\frac{\partial u}{\partial y}+\frac{\partial v}{\partial x} & =\frac{\mathrm{I}}{\mu} \tau_{x y} .
\end{aligned}
$$

For the calculation of $S_{\mathrm{N}^{\prime}}$ Bucher took Equation (55) neglecting the second term in brackets, and Equation $\left(5^{6}\right)$ disregarding the first term on the left-hand side. As boundary conditions are assumed a stress-free surface, $v=0$, on the ground (no gliding) and at the wall, and for $y \rightarrow-\infty$ the state in the neutral zone.

$S_{\mathbf{Q}^{\prime}}$ is calculated with Equation (55), the left-hand side being zero, and with Equation (56), neglecting the second term on the left-hand side. The boundary conditions are a vanishing $u$ at the wall and on the ground, furthermore the state of the neutral zone for $y \rightarrow-\infty$. A stress-free surface is not assumed (shear stresses $\tau_{y x}$ are zero at the surface because of the symmetry of the stress tensor $\left.\tau_{y x}=\tau_{x y}\right)$. The above assumptions mean that Bucher's result is only valid for low-density snow and that the distribution of $S_{Q^{\prime}}$ near the surface is not correct.

With the equilibrium equations for plane strain and the replacement of the parabolic function (Equations (24) and (26)) for the boundary condition $y \rightarrow-\infty$ (neutral zone) by a sine function, Bucher gets for the velocity parallel to the slope for o $>y>-\infty$

$$
v=v_{\infty}\left[\mathrm{I}-\exp \left\{+\frac{\pi}{2} \frac{y}{D}\left(\frac{m-\mathrm{I}}{2 m}\right)^{\frac{1}{2}}\right\}\right],
$$


where

$$
v_{\infty}=v_{\infty_{0}} \sin \left(\frac{\pi}{2} \frac{D-x}{D}\right)
$$

and

$$
v_{\infty 0}=\gamma \sin \psi \frac{\mathrm{I}}{\mu} \frac{D^{2}}{2}
$$

the velocities in the neutral zone. Theoretically the back-pressure zone extends over an infinite distance. Practically, when $95 \%$ of the undisturbed velocity is reached, the wall influences the snow cover over a distance of

$$
y_{\mathrm{b}}=-\frac{6}{\pi} D\left(\frac{2 m}{m-1}\right)^{\frac{1}{2}},
$$

which is in good agreement with Haefeli's value of Equation (47) when no gliding is assumed. The normal stress for $y=0$ is

$$
\sigma_{y}=-\frac{\pi}{2 D} \mu\left(\frac{2 m}{m-1}\right)^{\frac{1}{2}} v_{\infty}
$$

i.e. proportional to the creep velocity in the neutral zone. From this the resultant becomes

$$
S_{\mathrm{N}}{ }^{\prime}=-\frac{\gamma}{2} \sin \psi D^{2}\left(\frac{2 m}{m-\mathrm{I}}\right)^{\frac{1}{2}},
$$

and analogously the resultant of the stresses parallel to the wall

$$
S_{\mathbf{Q}^{\prime}}=-\frac{\gamma}{2} \cos \psi D^{2}\left(\frac{m-2}{2(m-\mathrm{I})}\right)^{\frac{1}{2}}=-\frac{\gamma}{2} \cos \psi D^{2}\left(\tan \beta_{45^{\circ}}\right)^{\frac{1}{2}} \text {. }
$$

Finally for the angle $\epsilon$ a similar expression as Equation ( $5 \mathrm{I})$ is obtained:

$$
\tan \epsilon=\frac{S_{\mathrm{Q}^{\prime}}}{S_{\mathrm{N}^{\prime}}}=+\frac{\mathrm{I}}{\tan \psi}\left(\frac{m-2}{4^{m}}\right)^{\frac{1}{2}} \text {. }
$$

Attempts have been made by de Quervain and Roch (de Quervain and Figilister, I953) to generalize Bucher's result for gliding. For the velocity profile they assumed a sine or parabolic function whose zero point lies below the ground. The resultant correlation between snow pressure $S_{\mathrm{N}}$ ' and the relative glide velocity $n$ (glide factor) does not differ very much from that of Haefeli (Equations (49) and (44)). A criticism may apply in view of the concept of the stagnation depth (Section 3.2), implying a depth given by the tangent to the velocity profile at the ground. If this is done and the stagnation depth is known, instead of $D$ in Bucher's formula, a fictitious $D_{\mathrm{f}}$

$$
D_{\mathrm{f}}=+\left(2 D d_{\mathrm{ap}}{ }^{\prime}+D^{2}\right)^{\frac{1}{2}},
$$

has to be introduced (assumption of a parabolic function).

Regarding Equation (6o), a generalization of Bucher's snow-pressure formula to an arbitrary snow cover seems possible with an analogous procedure to that described in Section 3. I, i.e. subdividing the snow cover into layers with constant material characteristics. Integration of Equation (6o) over $\Delta D_{i}$ yields with a known velocity profile (same notation as in Figs $\mathrm{I}$ and 3 )

$$
S_{\mathrm{N}^{\prime}}=-\frac{\pi}{4} \sin \psi \frac{\gamma_{i}}{d_{\mathrm{f} i}}\left(\frac{2 m_{i}}{m_{i}-\mathrm{I}}\right)^{\frac{1}{2}}\left[\Delta D_{i}\left(d_{\mathrm{f} i}{ }^{2}-e_{i}^{2}\right)-\frac{x_{i}^{3}-x_{i-1}{ }^{3}}{3}-e_{i}\left(x_{i}^{2}-x_{i-\mathrm{I}}{ }^{2}\right],\right.
$$

where $d_{\mathbf{f} i}$ is a fictitious thickness

$$
d_{\mathrm{f} i}{ }^{2}=v_{0 i-\mathrm{I}} \frac{2 \mu_{i}}{\gamma_{i} \sin \psi}+\left(x_{i-1}+e_{i}\right)^{2}
$$


and

$$
e_{i}=\frac{v_{0 i-1}-v_{0 i}}{2 \Delta D_{i}} \frac{2 \mu_{i}}{\gamma_{i} \sin \psi}-\frac{\mathrm{I}}{2}\left(x_{i}-x_{i-1}\right) .
$$

For $\Delta D_{i}=D$ and no gliding, Equation (65) again furnishes Bucher's result (Equation (6I)), but larger by a factor of $\pi / 3$, a consequence of integration of the parabolic instead of the sine function.

Shoda ([1975]) similarly tried to generalize Haefeli's snow-pressure theory by assuming a multi-layered snow-pack. His complicated results however do not fit the requirements for practical use.

Field observations using sawdust columns exhibit in many cases a triangular creep profile. Because of this fact, Mellor (1968) and McClung (unpublished) assumed a shear viscosity proportional to the first invariant of the stress tensor, * i.e. quasi-Newtonian behaviour. In the neutral zone the first invariant $\sigma_{(\mathrm{I})}$ is

$$
\sigma_{(\mathrm{I})}=\sigma_{x}+\sigma_{y}+\sigma_{z}=\frac{m+\mathrm{I}}{m-\mathrm{I}} \sigma_{x},
$$

if a constant cross-section number is assumed ("semi-quasi-Newtonian behaviour"). With constant density, $\sigma_{x}$ increases linearly with $x$, the viscosity can therefore be written as

$$
\mu=c x \text {, }
$$

and the velocities in the neutral zone become

$$
u=\frac{m-2}{2 c(m-\mathrm{I})} \gamma \cos \psi(D-x),
$$

and in so far as gliding takes place

$$
v=\frac{\gamma \sin \psi}{c}\left(D+d_{\mathrm{ap}}{ }^{\prime}-x\right) .
$$

Because of a common property of the quasi-Newtonian and the semi-quasi-Newtonian fluid with the Newtonian fluid, a restriction exists for the choice of shear viscosity and crosssection number of quasi-linear constitutive equations. Let $\mu^{\prime}$ and $m^{\prime}$ be stress-dependent values for uniaxial compression and $\mu^{\prime \prime}$ and $m^{\prime \prime}$ those for uniaxial tension. Superposing a principal compression stress $\sigma_{x}=\sigma_{1}$ on a principal tension $\sigma_{y}=\sigma_{2}$, we get the rates of deformation:

$$
\begin{aligned}
& \frac{\partial u}{\partial x}=\frac{\sigma_{x}}{2 \mu^{\prime}\left(\mathrm{I}+\frac{\mathrm{I}}{m^{\prime}}\right)}-\frac{\sigma_{y}}{2 \mu^{\prime \prime}\left(\mathrm{I}+m^{\prime \prime}\right)}, \\
& \frac{\partial v}{\partial y}=\frac{\sigma_{y}}{2 \mu^{\prime \prime}\left(\mathrm{I}+\frac{\mathrm{I}}{m^{\prime \prime}}\right)}-\frac{\sigma_{x}}{2 \mu^{\prime}\left(\mathrm{I}+m^{\prime}\right)}, \\
& \frac{\partial w}{\partial z}=-\frac{\sigma_{x}}{2 \mu^{\prime}\left(\mathrm{I}+m^{\prime}\right)}-\frac{\sigma_{y}}{2 \mu^{\prime \prime}\left(\mathrm{I}+m^{\prime \prime}\right)} .
\end{aligned}
$$

For simple shear $\sigma_{x}=-\sigma_{y}$ and $\sigma_{z}=0, \partial w / \partial z$ has to vanish in accordance with the constitutive equation. Therefore the general condition

$$
\mu^{\prime}\left(\mathrm{I}+m^{\prime}\right)=\mu^{\prime \prime}\left(\mathrm{I}+m^{\prime \prime}\right)
$$

exists, i.e. stress dependent functions $\mu$ and $m$ have to become equal for pure shear. Assumption (69) with constant $m$ is in agreement with the above condition.

* Which is certainly not generally valid, e.g. for pure shear the first invariant is zero! 
McClung (unpublished) calculated the stresses $\sigma_{y}$ on a barrier for the two-dimensional case by the finite-element method, assuming a viscosity proportional to the first invariant of the stress tensor and the glide law Equation (40) with the same stress-dependent viscosity. Density and cross-section number are taken constant. As boundary conditions he took a stress-free surface, disappearing velocity $v$ at the barrier and not only an ideally rough $(u=0)$ but also a smooth surface $\left(\tau_{x y}=0\right)$ of the obstacle. The calculations up-slope were continued until the velocities (and stresses) returned to their neutral-zone values (Equation (7I)), which defined the back-pressure zone.

An application of plasticity theory to snow mechanics is described by Ziegler ( 1963 , [1975]). He idealizes snow as a rigid-plastic incompressible material, which make the relevance of his results generally questionable, except probably for loose new snow and a snow cover at the melting point. The two-dimensional case of a uniformly thick and not gliding slab, terminated at its lower end by a rigid rough barrier is treated. The goal of the paper is to get an expression for the maximum spacing of barriers given by the critical state of the slab, i.e. when plastic flow occurs. For this state he obtains for the critical thickness

$$
D_{\mathrm{cr}}=\frac{k}{\gamma \sin \psi}
$$

where $k$ is the yield stress in pure shear (von Mises yield criterion), a normal stress on the wall

$$
\sigma_{y}=-k\left[\frac{x}{D} \cot \psi+2\left(\mathrm{I}-\frac{x^{2}}{D^{2}}\right)^{\frac{1}{2}}\right],
$$

and a corresponding resultant force

$$
S_{\mathrm{N}^{\prime}}=-k \frac{D}{2}(\cot \psi+\pi) .
$$

(The requirement of the creep number is not fulfilled because of the different idealization of the material.) For the critical distance between two rows of barriers, i.e. the minimum where sliding can occur, Ziegler ([1975]) obtains

$$
L_{\mathrm{cr}}=\frac{k}{\gamma} \frac{\cot \gamma+3 \pi}{2 \sin \psi},
$$

which may be considered as a back-pressure zone.

In Figure 13 an example calculated by the finite-element method for an ideal rough wall based on field observations (McClung, unpublished) is shown. It has been performed with a stress-dependent viscosity (proportional to the first invariant) but also for a constant value. Its difference is surprisingly small. All further possibilities presented for the calculation of the normal stress are also plotted in the figure. The observed data were:

$$
\begin{array}{rlrl}
D & =3.54 \mathrm{~m}, & \psi & =45^{\circ}, \\
d^{\prime} & =d_{\mathrm{ap}}^{\prime}=\mathrm{I} . \mathrm{I} 3 \mathrm{~m}, \quad \mathcal{N}=\mathrm{I} .40, \\
\gamma & =546 \mathrm{kp} \mathrm{m}^{-3}, & m & =3.33, \\
\tan \beta_{45^{\circ}} & =0.286 . & &
\end{array}
$$

Equation (74) by Ziegler furnishes the largest pressure if $k$-playing the most important part in his relations - is calculated from Equation (73) assuming that $D=D_{\text {cr. }}$. The second term in square brackets of Haefeli's Equation (49) - the creep pressure - delivers a stress close to the maximum of McClung's stress distribution of variable viscosity. Bucher's pressure Equation (6o), generalized for gliding by Equation (64), is at its maximum the same as Haefeli's creep pressure, but essentially smaller in the lower part of the wall. A triangular velocity profile in the neutral zone (Equation (7I)) was assumed for the method of the multilayered snow-pack (Equation (65)). The resultant force is the smallest, but the pressure distribution seems realistic. Brown and Evans ([r975]) calculated the same example as 


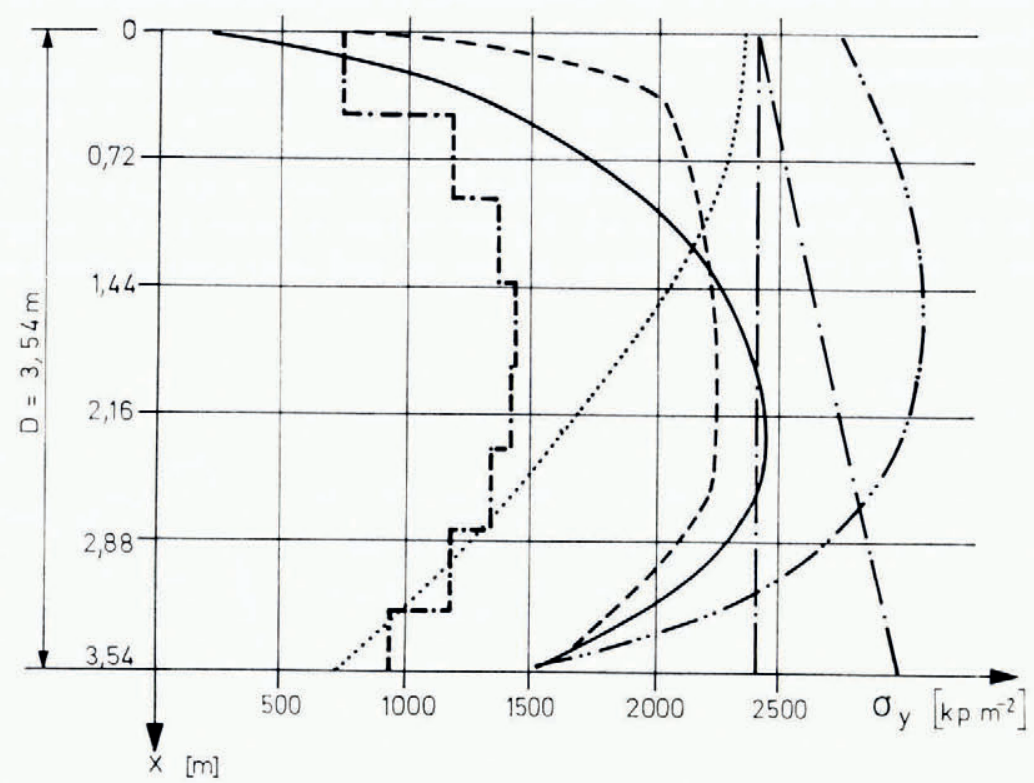

Fig. 13. Comparison of the different calculation methods for the normal stress on a rigid obstacle when the same characteristic of the snow cover are assumed throughout.

$$
\begin{aligned}
& -\cdots-\text { Equation }(65) \\
& -\cdots-\text { Ziegler, Equation (74) } \\
& -\cdots-\text { Haefeli, Equation (49) } \\
& \cdots \cdots \cdots . \text { Bucher, Equations (6o) and (64) } \\
& \cdots \cdots-\text { McGlung (unpublished) constant viscosity } \\
& \text { McClung (unpublished) variable viscosity }
\end{aligned}
$$

given above, also making use of the finite-element method. Like McClung, they took a viscosity proportional to the first invariant of the stress tensor and furthermore presumed that during deformation plane sections remain plane (also within the back-pressure zone) and that the shear stress on the ground is proportional to the basal velocity. The resultant average stress is $\sigma_{y}=\mathrm{I} 750.5 \mathrm{kp} \mathrm{m}^{-2}$, similar to that of Bucher. The back-pressure zone, when using the different methods, becomes:

$$
\begin{array}{ll}
\text { McClung (variable viscosity) } & -28.0 \mathrm{~m} \\
\text { Haefeli (Equation (47)) } & -15.6 \mathrm{~m} \\
\text { Bucher (Equations (59) and (64)) } & -14.6 \mathrm{~m} \\
\text { Ziegler (Equation (76)) } & -18.4 \mathrm{~m} \\
\text { Equation (66) and (59) } & -4.8 \mathrm{~m} \text { (topmost layer) up to } \\
\text { Brown and Evans ([1975]) } & -14.6 \mathrm{~m} \text { (lowest layer) }
\end{array}
$$

In favour of the multi-layer model it must be said that an increase of $y_{\mathrm{b}}$ towards ground seems realistic. Unfortunately the "truth" of the above calculations cannot be found, because of the lack of snow-pressure measurements.

At Weissfluhjoch (altitude $268 \mathrm{om}$ ), Switzerland, for many years snow force measurements have been performed on a supporting structure (DAI) which is erected perpendicular to the slope and $3.2 \mathrm{~m}$ in height. This structure consists of three parts, a central field $(4 \mathrm{~m}$ in length) for the measurement of the forces on the infinitely long barrier, and on each side of it 
a boundary field ( $2 \mathrm{~m}$ in length) for the measurement of the end-effect forces. On each horizontal crossbeam the forces perpendicular $\left(S_{\mathbf{N b}^{\prime}}\right)$ and parallel $\left(S_{\mathbf{Q b}^{\prime}}\right)$ to the supporting structure were measured by the deformation of springs. No or almost no gliding occurs on the $37^{\circ}$ inclined slope. The measurements (Kümmerli, I958) served-besides theoretical investigations - as main basis for the establishment of snow forces in the Swiss guidelines for avalanche control in the starting zone (Switzerland. Eidg. Institut für Schnee- und Lawinenforschung, I968). In Figures I4, I5 and 16 some results referring to the central field are given. Figure ${ }_{14}$ shows the resultant force $S_{\mathrm{N}^{\prime}}$ and $S_{\mathrm{Q}^{\prime}}$ and some related characteristics as a

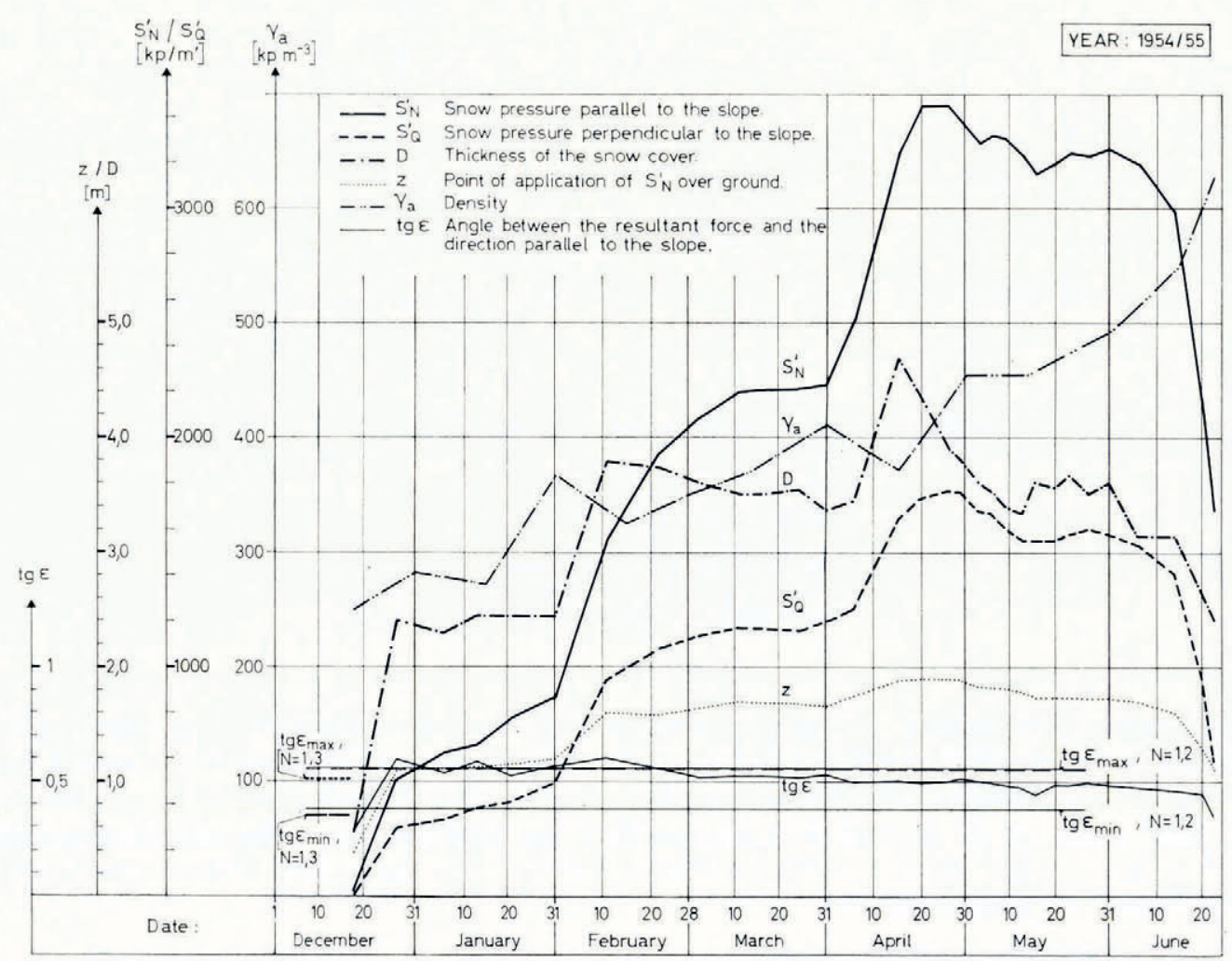

Fig. 14. Snow force field tests at Weissfluhjoch/Davos. Resultant snow forces and associated characteristics as a function of time.

function of time. The development of $S_{\mathrm{N}^{\prime}}$ and $S_{\mathrm{Q}^{\prime}}$ is similar, however $\tan \epsilon$ decreases with increasing density (compare Equation $\left(6_{3}\right)$ with Equations (2 I) or (22)). In this context it has to be mentioned that the Swiss guidelines distinguish two types of loading of structures. The first type is based on an extreme snow depth (equal to the maximum height of the structure) but having only a relatively low average snow density $\gamma_{\mathrm{a}}=270 \mathrm{kp} \mathrm{m}^{-3}$. The second type takes into consideration only a partial covering of the structure- $77 \%$ of the extreme snow depth-but allows for an increased snow density $\gamma_{\mathrm{a}}=400 \mathrm{kp} \mathrm{m}^{-3}$. The same resultant force is assumed for this type, which leads to higher stresses. Figure 14 shows the maximum $\tan \epsilon$ (Equation (52)) corresponding to $a=0.5$. For the determination of the minimum, only ranges with a snow depth of at least $77 \%$ of the maximum of the winter in question were considered. From this it turned out that $a$ never becomes smaller than 0.35 
SNOW FORCES

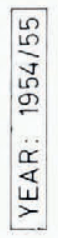
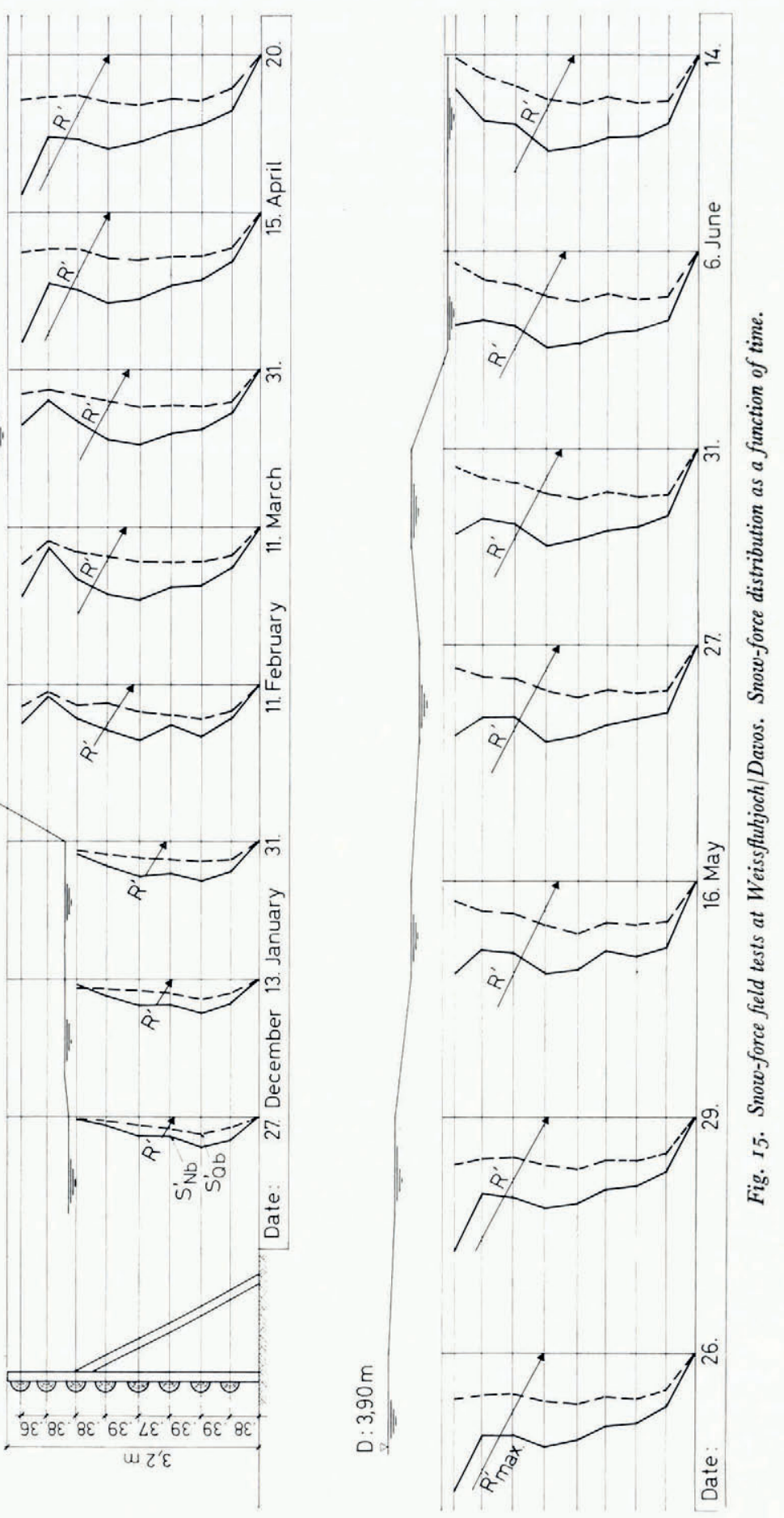
(de Quervain and Salm, I963). The point of application of the resultant force always lies in about the half of the snow depth, but cannot however follow quick increases of $D$ because of the fact that newly fallen snow causes smaller stresses. Figure 14 demonstrates generally the development of the forces with densification. In Figure $I_{5}$ the pressure distribution exhibits a similar shape to that of McClung (with variable viscosity) or that of the multi-layer model in Figure I3. An exception occurs when the snow thickness exceeds the height of the structure (end-effect). The stress distribution at the moment of the maximum resultant force of a winter is shown in Figure 16 for a period of 6 years. The above remarks are verified by this plot.
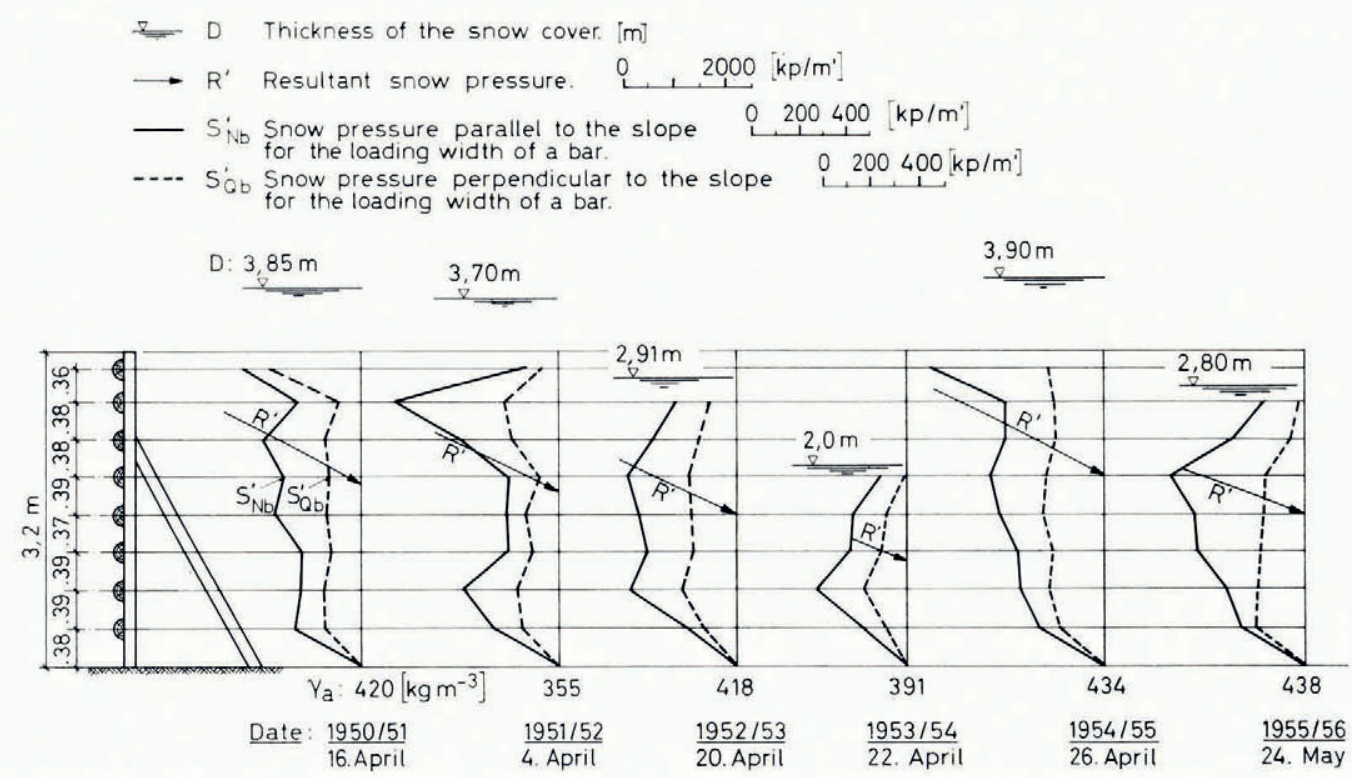

Fig. 16. Snow-force field tests at Weissfluhjoch/Davos. Distribution of the snow forces at the time of maximum resultant snow force of one winter.

If the extension of the supporting plane across the slope is confined in length, end-effect forces will be present. These forces are due to the three-dimensional viscous flow around the supporting plane. This becomes evident when a Newtonian fluid is considered, where the stresses are proportional to the gradient of velocity (see, e.g. Equation (55)). Towards the end of a barrier this gradient becomes larger than that of an infinitely long wall, because of the velocity component $w$ in $z$-direction. At the same time the back-pressure zone decreases towards the end but lateral shear stresses $\tau_{z y}$ reduce the velocities in a lateral zone exceeding the length of the structure, creating there a compressive zone up the slope and a tensile zone down the slope.

For a single structure - i.e. no interference with other structures-Haefeli (I942, I 95 I) made a first attempt at the calculation. He introduced the efficiency $\eta_{F}$ of a structure with regard to snow pressure, i.e. the ratio of the real force to that on the infinitely long plane, acting over the same length. On the basis of Equations (Io) and (I I) for $y=0$ he got

$$
\eta_{\mathrm{F}}=\frac{\pi}{2} \frac{\mathrm{I}+a \cos \alpha}{\alpha-2 \tan \alpha \ln \sin \alpha},
$$


where

$$
\tan \alpha=\frac{b}{y_{\mathrm{b}}} .
$$

The length of the structure equals $2 b, y_{\mathrm{b}}$ is the length of the back-pressure zone and $\mathrm{o} \geqslant a \geqslant \mathrm{I}$ allows for the tensile zone down-slope of the structure (zero when disregarding this zone).

Obviously because it was felt that Equation (77) is overestimating the efficiency, in the Swiss guidelines of r955 (Switzerland. Eidg. Inspektion für Forstwesen, Jagd und Fischerei, [1955]) a different and much smaller value

$$
\eta_{\mathbf{F}}=\mathrm{I}+\frac{D}{2 b},
$$

was taken into consideration. Subsequent measurements and observations proved however the inadequacy of Equation (78), especially for gliding.

The author (Salm, 1960, in press) assumed an incompressible Newtonian fluid to describe approximately the flow near the end of and outside a laterally confined structure. The Hele-Shaw flow (Schlichting, r95I)

$$
\left.\begin{array}{rl}
u & =0, \\
v & =v_{(y, z)}\left[\mathrm{I}-\left(x^{2} / D^{2}\right)\right], \\
w & =w_{(y, z)}\left[\mathrm{I}-\left(x^{2} / D^{2}\right)\right],
\end{array}\right\}
$$

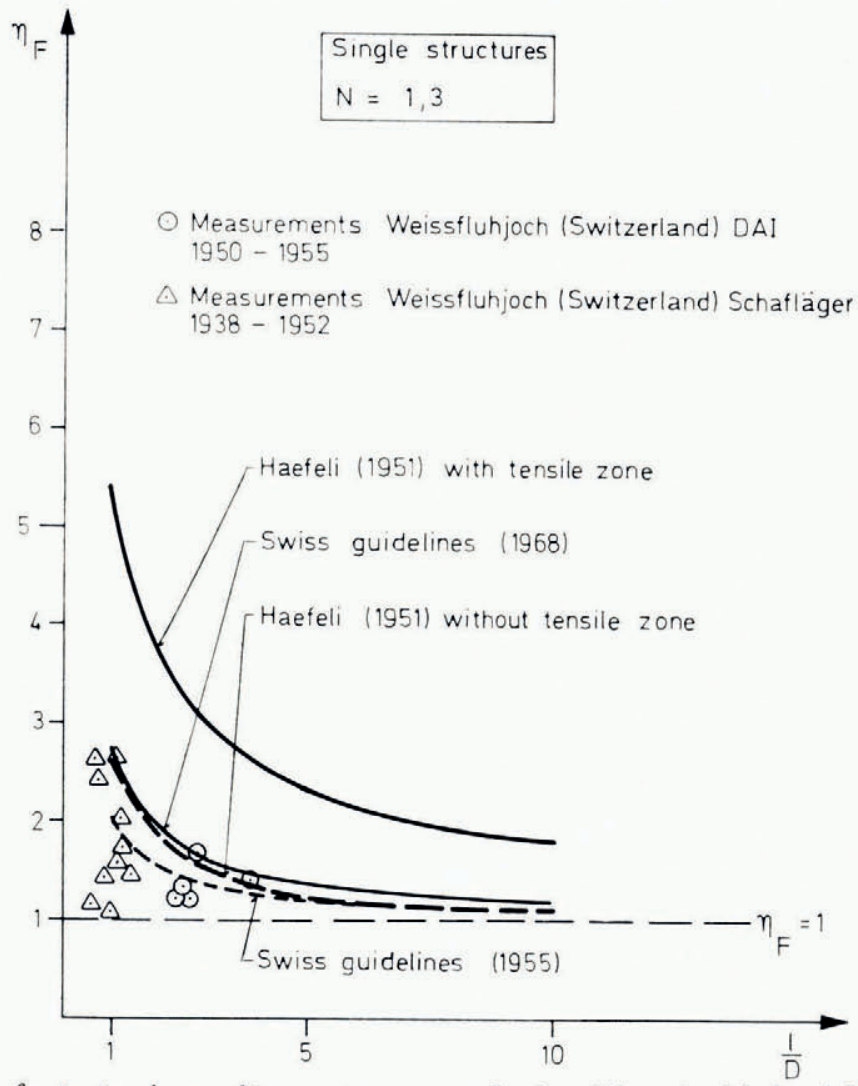

Fig. 17. Efficiency $\eta_{\mathrm{F}}$ of a structure in regard to snow pressure as a function of the ratio of the length $l$ of a structure and snow thickness $D$. 
96

is a solution for this three-dimensional problem. $v_{(y, z)}$ and $w_{(y, z)}$ are solutions of the plane potential flow fulfilling the boundary conditions $v=0$ for $y=0$ and $-b \leqslant z \leqslant b$, and $v=v_{\infty}$ (Equation (26)), $w=0$ for $y=-\infty$. Near the end of the structure the stressassumed to be proportional to the gradient of $v$ for $y=0$ - becomes

$$
\sigma_{y}=-\mu f_{(m)} \frac{b^{2}}{\left(b^{2}-z^{2}\right)^{\frac{3}{2}}} v_{\infty}
$$

where $f_{(m)}$ is a function of the cross-section number. The infinite stress for $z=b$ is assumed to be limited by the strength of snow. From this the end-effect force $S_{\mathrm{R}}{ }^{\prime}$ (an additional force to $S_{\mathrm{N}}{ }^{\prime}$ per unit length of the structure, operating parallel to the slope over the length $\Delta l$ ) of the Swiss guidelines (Switzerland. Eidg. Institut für Schnee- und Lawinenforschung, 1968) is obtained

$$
S_{\mathbf{R}}{ }^{\prime}=f_{\mathbf{R}} S_{\mathbf{N}^{\prime}}
$$

with the end-effect factor

$$
f_{\mathbf{R}}=\mathrm{I}+\mathrm{I} .25 \mathcal{N}
$$

and

$$
\Delta l=\frac{D}{3} .
$$

A comparison of the described methods with measurements is given in the Figures 17 and 18 .

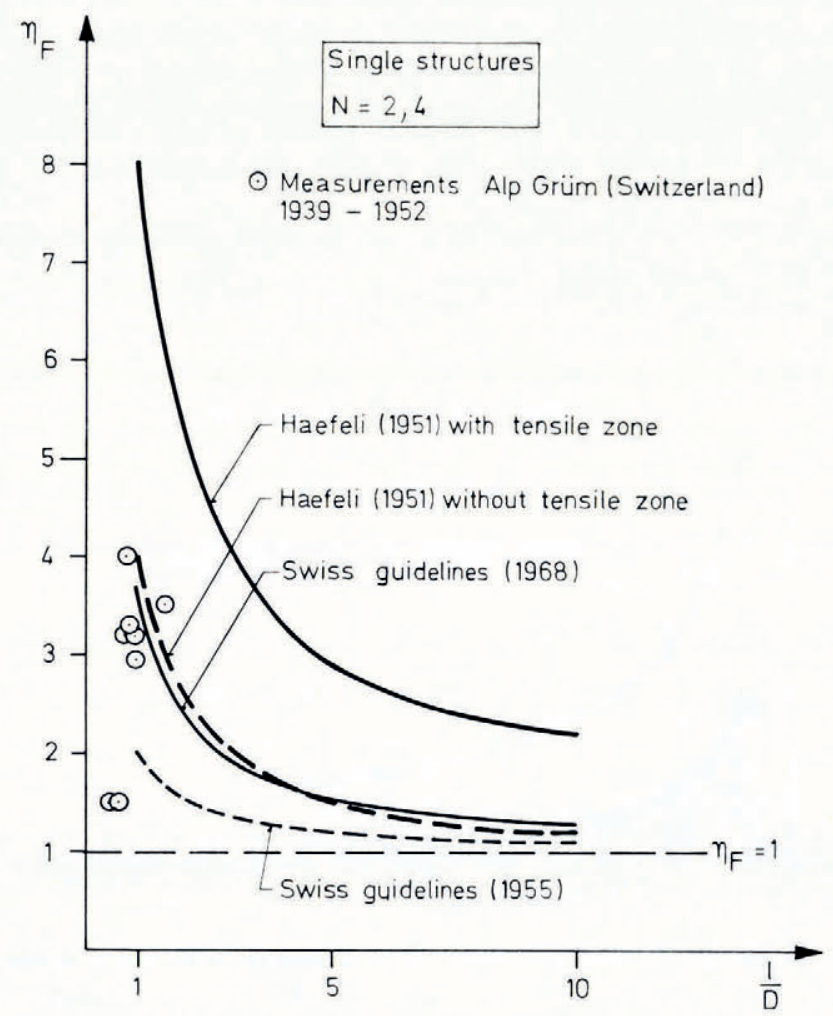

Fig. I8. Efficiency $\eta_{\mathrm{F}}$ of a structure in regard to snow pressure as a function of the ratio of the length $l$ of a structure and snow thickness $D$. 
Confined structures, arranged relatively close together in an interval $A$ across the slope, cannot be treated as described above. Certainly the end-effect forces decrease with decreasing $A$. In the Swiss guidelines of 1955 it was assumed that

$$
\eta_{\mathrm{F}}=\mathrm{I}+\frac{A}{2 b} \quad \text { for } A \leqslant D,
$$

whereas in the latest guidelines the following approximation was made. The maximum possible force acting in the interval $A$ consists in the fictitious pressure $S_{\mathrm{N}^{\prime}}$ (rigid plane in $A$ ) plus a traction originating from the down-slope snow cover, limited by the tensile strength. Together with a presumed linear dependence of $f_{\mathrm{R}}$ on $\mathcal{N}$ in analogy to Equation (82), this consideration led to

$$
f_{\mathbf{R}}=0.9^{2}+0.65 \mathcal{N}
$$

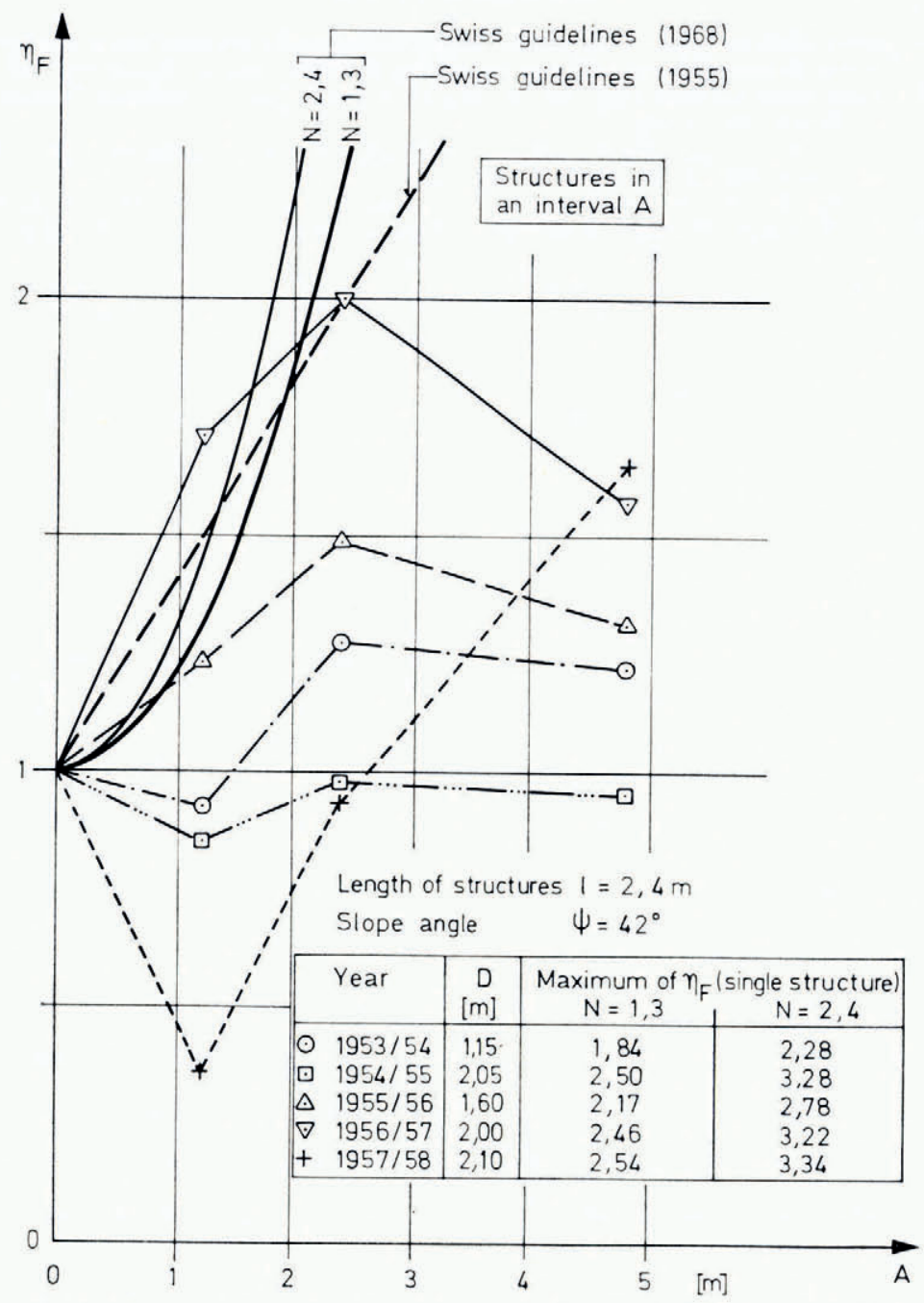

Fig. 19. Efficiency $\eta_{\mathrm{F}}$ of a structure in regard to snow pressure as a function of the lateral interval A. Field test data from Dorfberg test area (Davos). 
and

$$
\Delta l=0.60 \frac{A}{2} .
$$

The quantities in Equations (85) and (86) can obviously not become larger than those of Equations $(82)$ and $(83)$.

Measurements of the snow pressure with increasing $A$ have been performed in the test area of Dorfberg/Davos, Switzerland. The results including the values of the guide-lines are plotted in Figure 19. The pressures were normalized to the values on the infinitely long wall and to a uniform snow thickness (by the ratios of $D^{2}$ ). At the test site the glide factor $\mathcal{N}$ varies between I.3 and 2.4. The scatter of the results is large, the guide-lines 1968 cover, however, the steepest measured increase of the forces with $A$.

\section{REFERENGES}

Allen, D. E. 1956. Snow loads on roofs. The present requirements and a proposal for a survey of snow loads on roofs. Canada. National Research Council. Division of Building Research. Internal Report No. 106.

Allen, D. E. 1958. Snow loads on roofs $1956-57$. A progress report. Canada. National Research Council. Division of Building Research. Internal Report No. 134 .

Allen, D. E., and Turkstra, C. J. 1958. Snow loads on roofs 1957-58. Second progress report. Canada. National Research Council. Division of Building Research. Internal Report No. $6_{3}$.

Bader, H., and others. 1939. Der Schnee und seine Metamorphose, von H. Bader, R. Haefeli, E. Bucher, J. Neher, O. Eckel, C. Thams, P. Niggli. Beiträge zur Geologie der Schweiz. Geotechnische Serie. Hydrologie, Lief. 3. [English translation: U.S. Snow, Ice and Permafrost Research Establishment. Translation 14, 1954.]

Bader, H., and others. 1951. Preliminary investigations of some physical properties of snow, by H. Bader, B. L. Hansen, J. H. Joseph and M. A. Sandgren. U.S. Snow, Ice and Permafrost Research Establishment. Report 7.

Brown, C. B., and Evans, R. J. [1 1975.] Effect of glide and creep on rigid obstacles. [Union Géodésique et Géophysique Internationale. Association Internationale des Sciences Hydrologiques. Commission des Neiges et Glaces.] Symposium. Mécanique de la neige. Actes du colloque de Grindelwald, avril 1974, p. 407-14. (IAHS-AISH Publication No. 114.$)$

Brown, C. B., and others. 1973. Incorporation of glide and creep measurements into snow slab mechanics, by C. B. Brown, R. J. Evans and D. [M.] McClung. U.S. Dept. of Agriculture. Forest Service. General Technical Report RM-3, p. 7-13.

Bucher, E. 1948. Beitrag zu den theoretischen Grundlagen des Lawinenverbaus. Beiträge zur Geologie der Schweiz. Geotechnische Serie. Hydrologie, Lief. 6.

Deutsches Institut für Normung. 1975. Lastannahmen für Bauten. Verkehrslasten, Schneelast und Eislast. Berlin, Köln, Beuth Verlag. (DIN r 055.)

Gand, H. R. in der, and Zupančič, M. 1966. Snow gliding and avalanches. Union de Géodésie et Géophysique Internationale. Association Internationale d'Hydrologie Scientifique. Commission pour la Neige et la Glace. Division Neige Saisonnière et Avalanches. Sympsium international sur les aspects scientifiques des avalanches de neige, 5-10 avril 1965, Davos, Suisse, p. 230-42. (Publication No. 69 de l'Association Internationale d'Hydrologie Scientifique.)

Haefeli, R. I942[a]. Spannungs- und Plastizitätserscheinungen der Schneedecke. Mitteilungen aus der Versuchsanstalt für Wasserbau an der Eidg. Technische Hochschule (Zürich), Nr. 2.

Haefeli, R. I942[b]. Streifenlastversuche. Theorie zum Streifenlastapparat. Interner Bericht der Station Weissfluhjoch über Schnee- und Lawinen im Winter $194 \mathrm{I} / 42$.

Haefeli, R. 1948. Schnee, Lawinen, Firn und Gletscher. (In Bendel, L., ed. Ingenieur-Geologie. 2. Bd. Wien, Springer-Verlag, p. 663-735.)

Haefeli, R. 1951. Neuere Entwicklungstendenzen und Probleme des Lawinenverbaus im Anbruchgebiet. Mitteilungen des Eidg. Institutes für Schnee- und Lawinenforschung, Nr. 9, p. 28-56.

Haefeli, R. Ig66. Considérations sur la pente critique et le coefficient de pression au repos de la couverture de neige. Union de Géodésie et Géophysique Internationale. Association Internationale d'Hydrologie Scientifique. Commission pour le Neige et la Glace. Division Neige Saisonnière et Avalanches. Symposium international sur les aspects scientifiques des avalanches de neige, 5-10 avril 1965 , Davos, Suisse, p. 141-53. (Publication No. 69 de l'Association Internationale d'Hydrologie Scientifique.)

International Organization for Standardization. 1974. Snow loads on roofs. Fourth draft proposal from Norges Byggstandardiseringsråd. Oslo, International Organization for Standardization.

Kümmerli, F. 1958. Auswertung der Druckmessungen am Druckapparat Institut (DAI). Interner Bericht des Eidg. Institutes für Schnee- und Lawinenforschung, Nr. 240.

Landauer, J. K. 1957. Creep of snow under combined stress. U.S. Snow, Ice and Permafrost Research Establishment. Research Report $4^{1}$.

Lutes, D. A. 1970. Snow loads for the design of roofs in Canada. Proceedings of the Western Snow Conference, 38 th annual meeting, p. $6 \mathrm{r}-67$.

McClung, D. M. [1975.] Creep and the snow-earth interface condition in the seasonal alpine snowpack. [Union Géodésique et Géophysique Internationale. Association Internationale des Sciences Hydrologiques. Commission des Neiges et Glaces.] Symposium. Mécanique de la neige. Actes du colloque de Grindelwald, avril 1974, p. 236-48. (IAHSAISH Publication No. I 14.) 
McClung, D. M. Unpublished. Avalanche defense mechanics. [Ph.D. thesis, University of Washington, Seattle, Washington, 1974.]

Martinec, J. 1977. Expected snow loads on structures from incomplete hydrological data. Fournal of Glaciology, Vol. 19, No. 81, p. 1 85-95.

Mellor, M. 1968. Avalanches. U.S. Cold Regions Research and Engineering Laboratory. Cold regions science and engineering. Hanover, N.H., Pt. III, Sect. A3d.

Nye, J. F. 1969. A calculation on the sliding of ice over a wavy surface using a Newtonian viscous approximation. Proceedings of the Royal Society of London, Ser. A, Vol. 31 I , No. I 506, p. 445-67.

Perla, R. I. 1971. The slab avalanche. Alta Avalanche Study Center Report (U.S. Forest Service, Alta, Utah) 100.

Perla, R. I. 1972. Generalization of Haefeli's creep-angle analysis. Journal of Glaciology, Vol. I I, No. 63, p. $447^{-}-50$.

Quervain, M. R. de. 1966. Measurements on the pressure at rest in a horizontal snow cover. Union de Géodésie et Géophysique Internationale. Association Internationale d'Hydrologie Scientifique. Commission pour la Neige et la Glace. Division Neige Saisonnière et Avalanches. Symposium international sur les aspects scientifiques des avalanches de neige, 5-IO avril 1965, Davos, Suisse, p. 154-59. (Publication No. 69 de l'Association Internationale d'Hydrologie Scientifique.)

Quervain, M. R. de, and Figilister, R. I953. Zum Schneedruckproblem. Winterbericht des Eidg. Institutes für Schnee- und Lawinenforschung, Nr. 16, p. 89-98.

Quervain, M. R. de, and Salm, B. 1963. Lawinenverbau im Anbruchgebiet. Kommentar zu den Richtlinien für den permanenten Stützverbau vom Februar $196 \mathrm{r}$. Mitteilungen des Eidg. Institutes für Schnee- und Lawinenforschung, Nr. 19.

Roch, A. 1948. Discussion sur la valeur du nombre de Poisson $m$ pour la neige. Interner Bericht des Eidg. Institutes für Schnee- und Lawinenforschung, Nr. 89.

Salm, B. 196o. Einige Bemerkungen zum Schneedruckproblem. Winterbericht des Eidg. Institutes für Schnee- und Lawinenforschung, Nr. 24, p. 145-50.

Salm, B. 1971. On the rheological behavior of snow under high stresses. Contributions from the Institute of Low Temperature Science, Hokkaido University, Ser. A, No. 23.

Salm, B. In press. Eine Stoffgleichung für die kriechende Verformung von Schnee.

Schlichting, H. 1951. Grenzschicht-Theorie. Karlsruhe, Verlag G. Braun.

Schriever, W. R., and others. [1975.] Measurements of snow and wind loads on full-scale buildings for improved design, by W. R. Schriever, D. E. Allen and W. A. Dalgliesh. Canada. National Research Council. Division of Building Research. Technical Paper No. 439.

Schweizerischer Ingenieur- und Architekten-Verein. 1970. Norm für die Belastungsannahmen, die Inbetriebnahme und die Uberwachung der Bauten. Zürich, Schweizerischer Ingenieur- und Architekten-Verein. (Norm SIA I6o.)

Shoda, M. [1975.] On the extension of Haefeli's one-dimensional theory of stress distribution within a sloping snow cover. [Union Géodésique et Géophysique Internationale. Association Internationale des Sciences Hydrologiques. Commission des Neiges et Glaces.] Symposium. Mécanique de la neige. Actes du colloque de Grindelwald, avril 1975, p. 415-24. (IAHS-AISH Publication No. 114 .)

Switzerland. Eidg. Inspektion für Forstwesen, Jagd und Fischerei. [1955.] Lawinenverbau im Anbruchgebiet. Vorläufige Richtlinien zur Dimensionierung von permanenten Stützverbauungen. [Bern], Eidg. Inspektion für Forstwesen, Jagd und Fischerei.

Switzerland. Eidg. Institut für Schnee- und Lawinenforschung. 1968. Lawinenverbau im Anbruchgebiet. Richtlinien des Eidg. Oberforstinspektorates für den Stützverbau. Mitteilungen des Eidg. Institutes für Schneeund Lawinenforschung, $\mathrm{Nr}$. 29.

Wakabayashi, R. 1975. Über Schneebruch in den japanischen Wäldern. Winterbericht des Eidg. Institutes für Schnee- und Lawinenforschung, Nr. 38, p. $135-47$.

Yosida, Z. [i.e. Yoshida, J.] 1963. Physical properties of snow. (In Kingery, W. D., ed. Ice and snow; properties, processes and applications: proceedings of a conference held at the Massachusetts Institute of Technology, February 12-I6, 1962. Cambridge, Mass., M.I.T. Press, p. 485-527.)

Ziegler, H. I 963 . Methoden der Plastizitätstheorie in der Schneemechanik. Zeitschrift für angewandte Mathematik und Physik, Vol. 14, Fasc. 6, p. 713-37.

Ziegler, H. [1975.] Continuum mechanics: a powerful tool in solving ice and snow problems. [Union Géodésique et Géophysique Internationale. Association Internationale des Sciences Hydrologiques. Commission des Neiges et Glaces.] Symposium. Mécanique de la neige. Actes duc colloque de Grindelwald, avril 1975, p. 185-95. (IAHS-A ISH Publication No. 114.)

\section{DISGUSSION}

E. R. LaChapelle: In the case of roof loading there is a third situation where the overhanging snow on the edge of a roof joins with the surrounding snow cover on the ground. This leads to the maximum roof load through settlement of the snow cover.

B. SALM: What I mentioned is certainly a minimum. Forces exceeding it have to be put into the remaining risk, which can be made smaller by assuming larger overhangs. Furthermore the calculation of this boundary force has to be as simple as possible. 
D. V. ReDdy: Have you carried out "flume tests" for snow drift in your Institute?

SALm: No, we did not carry out such tests.

D. M. MaClung: Do you have field measurements to support your proposed theory which features two mechanisms of snow gliding?

SALm: No, but I hope that somebody will perform them. The existence of the gliding mechanism associated with micro-roughness is proved by Haefeli's tests with the glass plate. To understand this mechanism better we need further laboratory tests with different ground material (e.g. a flat grass surface). The mechanism associated with macro-roughness becomes evident by your considerations in "Avalanche defense mechanics" (McGlung, unpublished). 